
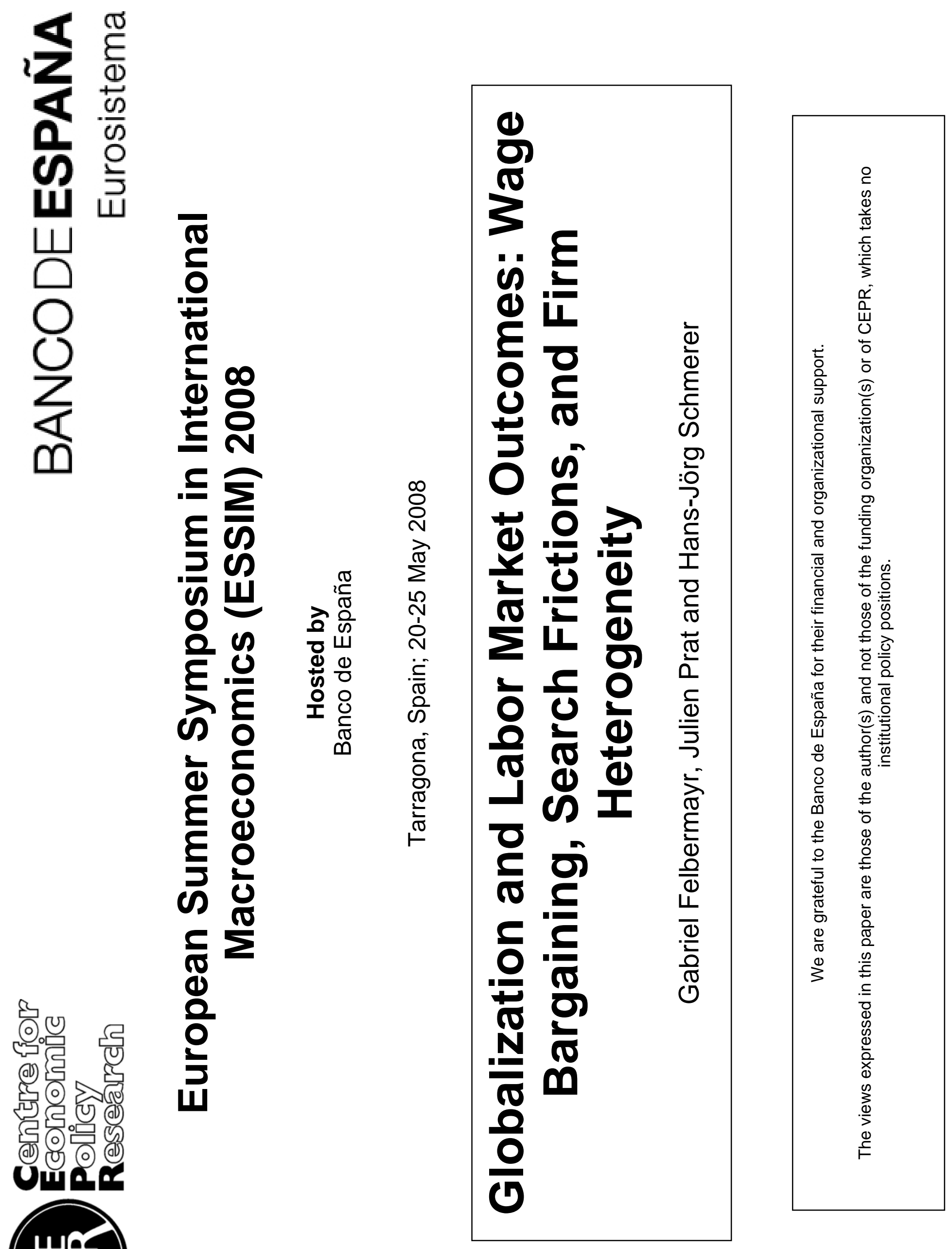


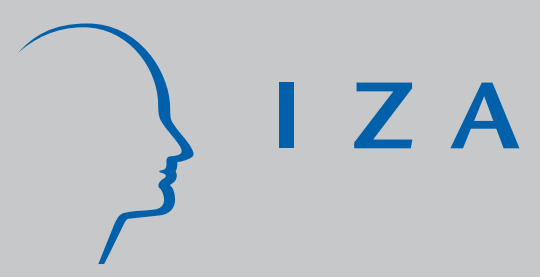

IZA DP No. 3363

Globalization and Labor Market Outcomes: Wage Bargaining, Search Frictions, and Firm Heterogeneity

Gabriel Felbermayr Julien Prat

Hans-J örg Schmerer

February 2008 


\title{
Globalization and Labor Market Outcomes: Wage Bargaining, Search Frictions, and Firm Heterogeneity
}

\author{
Gabriel Felbermayr \\ University of Tübingen \\ Julien Prat \\ University of Vienna \\ and IZA \\ Hans-Jörg Schmerer \\ University of Tübingen
Discussion Paper No. 3363
February 2008 \\ IZA \\ P.O. Box 7240 \\ 53072 Bonn \\ Germany \\ Phone: +49-228-3894-0 \\ Fax: +49-228-3894-180 \\ E-mail: iza@iza.org
}

\begin{abstract}
Any opinions expressed here are those of the author(s) and not those of IZA. Research published in this series may include views on policy, but the institute itself takes no institutional policy positions.

The Institute for the Study of Labor (IZA) in Bonn is a local and virtual international research center and a place of communication between science, politics and business. IZA is an independent nonprofit organization supported by Deutsche Post World Net. The center is associated with the University of Bonn and offers a stimulating research environment through its international network, workshops and conferences, data service, project support, research visits and doctoral program. IZA engages in (i) original and internationally competitive research in all fields of labor economics, (ii) development of policy concepts, and (iii) dissemination of research results and concepts to the interested public.
\end{abstract}

IZA Discussion Papers often represent preliminary work and are circulated to encourage discussion. Citation of such a paper should account for its provisional character. A revised version may be available directly from the author. 


\begin{abstract}
Globalization and Labor Market Outcomes: Wage Bargaining, Search Frictions, and Firm Heterogeneity*

We introduce search unemployment à la Pissarides into Melitz' (2003) model of trade with heterogeneous firms. We allow wages to be individually or collectively bargained and analytically solve for the equilibrium. We find that the selection effect of trade influences labor market outcomes. Trade liberalization lowers unemployment and raises real wages as long as it improves aggregate productivity net of transport costs. We show that this condition is likely to be met by a reduction in variable trade costs or the entry of new trading countries. On the other hand, the gains from a reduction in fixed market access costs are more elusive. Calibrating the model shows that the positive impact of trade openness on employment is significant when wages are bargained at the individual level but much smaller when wages are bargained at the collective level.
\end{abstract}

JEL Classification: F12, F15, F16

Keywords: trade liberalization, unemployment, search model, firm heterogeneity

Corresponding author:

Gabriel Felbermayr

University of Tübingen

Economics Department

Nauklerstrasse 47

72074 Tübingen

Germany

E-mail: gabriel.felbermayr@uni-tuebingen.de

\footnotetext{
* We are very grateful to Carl Davidson, Alan Deardorff, Hartmut Egger, Gino Gancia, Hugo Hopenhayn, Willi Kohler, Udo Kreickemeier, Omar Licandro, Marc Melitz, Gianmarco Ottaviano, Horst Raff, Rubén Segura-Cayuela, Jaume Ventura, as well as participants at the IAW anniversary conference, the $5^{\text {th }}$ ELSNIT Conference in Barcelona, and seminars at the Warsaw School of Economics, and the Universities of Leicester, Nottingham, Frankfurt, and Tübingen.
} 


\section{Introduction}

Public opinion meets globalization with mixed feelings. People agree that consumers benefit from trade but they are at the same time deeply concerned by its impact on job security. Fueled by numerous headlines about layoffs and outsourcing, many fear that globalization will worsen their prospects on the labor market. ${ }^{1}$ To a certain extent, economic theory can rationalize this fear. Workers who lose their jobs due to trade liberalization have to go through a period of active search before finding new employment opportunities. During this period of transition, job reallocations increase the amount of frictions in the labor market which mechanically pushes up the rate of unemployment. On the other hand, comparatively little is known about the long-run effect of trade liberalization on unemployment. This is largely because equilibrium theories of trade and labor are still poorly integrated. In this paper, we attempt to bridge the two literatures by proposing a framework which combines the currently dominant approaches in each field.

We integrate a slightly generalized version of Melitz's (2003) trade model with Pissarides' (2000) canonical model of equilibrium unemployment. Building on Hopenhayn (1992) and Krugman (1980), the Melitz-model shows how trade liberalization affects the productivity distribution of firms through selection of efficient firms into exporting and of inefficient firms into exit. That selection effect enjoys massive empirical support ${ }^{2}$ and constitutes a tangible source of gains from trade that the earlier literature has paid little attention to. Our analysis suggests that it also matters for labor market outcomes. We find that, for reasonable parameter values, the cleansing effect of trade lowers search unemployment. As the cost of vacancy posting relative to the productivity of the average firm decreases, employers intensify their recruitment efforts. This raises the ratio of job vacancies to unemployed workers, which leads to lower unemployment and higher real wages.

Our framework generalizes Melitz's and Pissarides' set-ups as follows. First, we allow for a flexible parameterization of the external scale effect through which input diversity affects aggregate productivity. This helps to disentangle the selection effect from the diversity-enhancing effect of trade modeled by Krugman (1980). It also addresses recent empirical evidence by Ardelean (2007) which puts the strength of the scale effect at a level substantially lower than the one implicitly assumed in the literature. ${ }^{3}$ We also need to adapt the search-matching framework,

\footnotetext{
${ }^{1}$ Scheve and Slaughter (2001) provide a detailed analysis of how American workers perceive globalization.

${ }^{2}$ See, among others, the surveys by Helpman (2006) or Bernard et al. (2007).

${ }^{3}$ Recent work by Corsetti et al. (2007) stresses the importance of external scale economies in a homogeneous-
} 
which builds on competitive product markets, to make it compatible with the assumption of monopolistic competition used in trade models of the Krugman (1980) tradition. Allowing for monopoly power on product markets implies that we have to abandon matches as our unit of analysis and consider instead multiple-worker firms. Given the existence of search frictions, this introduces the complication of intra-firm bargaining. We analyze two environments: individual bargaining, where each worker is treated as the marginal worker and which is closest to competitive wage setting; and collective bargaining, where management bargains about wages and employment with firm-level unions.

Although the model features firms with heterogeneous productivity, monopoly power on product markets, external economies of scale, and, due to search frictions, monopsony power on labor markets, we are able to characterize its equilibrium in closed-form. The aggregation procedure proposed by Melitz goes through with little modification because, regardless of the bargaining environment, firms with different productivity levels pay similar wages. We also obtain a useful separability result according to which the equilibrium average productivity of input producers is independent from labor market outcomes. Accordingly, the system of equilibrium conditions turns out to be recursive. One can follow the same steps than Melitz (2003) to compute the average productivity in the economy and then solve for the equilibrium in the labor market.

In the absence of scale economies, the labor market equilibrium can be derived as in the standard Mortensen-Pissarides model by interacting a job creation and a wage curve. Then, whether trade liberalization improves or worsens labor market outcomes depends solely on how it affects average productivity. Even though trade liberalization reallocates market shares towards efficient firms, exporters also incur transport costs that have to be deducted from the productivity gains. This is why trade liberalization does not necessarily enhance average productivity. We establish that both average productivity and employment always increase following a reduction in variable trade costs or an increase in the number of trade partners, as long as fixed foreign distribution costs are larger than domestic ones. Given that this requirement is satisfied by realistic calibrations of the model, such liberalization policies are likely to improve labor market outcomes. The gains of reducing fixed costs for foreign firms turn out to be more elusive because such a change benefits almost exclusively to new exporters.

Introducing external economies of scale drives a wedge between average and aggregate productivity. It complicates the analysis as we also have to take into account the positive relafirms, open macro model. 
tionship between input diversity and aggregate productivity. This new effect gives rise to an additional equilibrium relation and restricts the parameter space where the model admits a unique equilibrium. Setting aside these technical results, we find that scale economies do not modify the qualitative implications of the model. They actually reinforce the positive impact of trade liberalization by adding the variety-enhancing effect described in Krugman (1980) to the selection effect.

We conclude our analysis by a calibration exercise. Simulating various trade liberalization scenarios allows us to to sort out the ambiguities, in particular regarding the role of fixed foreign costs, and to assess the magnitude of the effects. The simulations predict that reducing variable trade costs, or increasing the number of trade partners, has a significantly positive impact on both wages and employment. The labor market effects of trade liberalization are strongly conditioned by the nature of the wage bargaining environment. When wages are negotiated collectively rather then individually, trade reform yields substantially lower unemployment gains, with aggregate productivity gains almost entirely absorbed by rising real wages. Moreover, results are sensitive with respect to the size of external scale economies; this calls for more empirical research into the parameters governing the model.

Related literature. This paper builds on our earlier work (Felbermayr and Prat, 2007) where we introduce search unemployment into a closed economy version of Melitz (2003) with the aim to study product market regulation. The relation to the present paper is straightforward, since trade liberalization can be understood as an alternative type of product market reform. In modeling bargaining regimes, we draw on Ebell and Haefke (2006), who analyze a closedeconomy, homogeneous firms model of search and unemployment.

There is a growing number of theory papers on the trade-unemployment relationship with heterogeneous firms. Our approach is closely related to the recent work of Egger and Kreickemeier (2007), who study the effect of trade liberalization in a model with fair wages. They find that trade increases the wage dispersion among identical workers and also leads to more unemployment. Davis and Harrigan (2007) find similar results for the degree of wage dispersion and unemployment, using an efficiency wages approach instead of fair wages.

There is a small but important literature on search unemployment in Heckscher-Ohlin trade models which goes back to Davidson et al. (1988). Building on this seminal line of research, three recent papers also discuss search unemployment in trade models with heterogeneous firms. The model closest to ours is presented by Janiak (2006). His framework exhibits an equilibrium 
under the assumption that the elasticity of substitution is smaller than two. As explained below, this restriction explains why Janiak's model predicts that trade liberalization raises equilibrium unemployment. In our model, equilibrium existence and uniqueness is guaranteed under less restrictive and more plausible conditions.

Mitra and Ranjan (2007) and Helpman and Itskhoki (2007) introduce search unemployment in two-sector models with heterogeneous firms. Their papers differ from ours in terms of motivation and setup: Mitra and Ranjan discuss the role of off-shoring; Helpman and Itskhoki focus on how labor market distortions diffuse internationally through trade. In contrast to our paper, Helpman and Itskhoki deviate from the standard search-and-matching framework as they disallow for forward-looking behavior of workers and firms on the labor market. Moreover, the symmetric version of their model (which is most easily comparable to our setup) features a negative trade-unemployment link: trade boosts average productivity in the differentiated goods sector, making employment there more attractive. This leads to a reallocation of labor from the distortion-free numéraire sector into the friction-ridden differentiated goods sector. ${ }^{4}$

Structure of the paper. The remainder of the paper is organized as follows. Section 2 lays-out the set-up of the model. In section 3, we analyze two ways of endogenizing wages: individual bargaining and efficient collective bargaining. In section 4, we describe exit and entry of firms. Section 5 studies the effects of three globalization scenarios: $(i)$ a reduction in variable trade costs, (ii) an increase in the number of trade relations, (iii) a reduction in fixed exporting costs. Section 6 calibrates the model in order to quantify the magnitude of the effects. Section 7 concludes. Proofs of the propositions, lemmata and corollaries are included in the Appendix.

\section{Setup of the Model}

We consider an economy that is essentially similar to the one analyzed in Melitz (2003) but for the existence of search frictions in the labor market. As in Melitz, the world is modeled as a collection of symmetric countries which interact on product markets. ${ }^{5}$ We deviate from existing treatments by explicitly parameterizing the external effect of increased input diversity on aggregate productivity.

\footnotetext{
${ }^{4}$ Davidson et al. (2007) propose a model with two-sided heterogeneity, where goods markets are perfectly competitive and firms endogenously choose technologies.

${ }^{5}$ For brevity, we skip the special case of autarky. Due to symmetry, we do not use country indices.
} 
Final output producers. The setup of the production side of our model is akin to Egger and Kreickemeier (2007). The single final output good, $Y$, is produced under conditions of perfect competition and can be either consumed or used as an input in the production process. Good $Y$ is assembled from a continuum of intermediate inputs, which may be produced domestically or imported, and which may command different equilibrium prices. Denoting the quantity of such an input $q(\omega)$, we posit the following production function

$$
Y=\left[M^{\frac{\nu-1}{\sigma}} \int_{\omega \in \Omega} q(\omega)^{\frac{\sigma-1}{\sigma}} d \omega\right]^{\frac{\sigma}{\sigma-1}}, \sigma>1, \nu \in[0,1],
$$

where the measure of the set $\Omega$ is the mass $M$ of available intermediate inputs, each produced by a monopolistically competitive firm. We refer to $M$ as the degree of input diversity while $\sigma$ denotes the elasticity of substitution between any two varieties of inputs.

To understand the role played by $\nu$, suppose that all varieties are demanded in identical quantities. Substituting $q(\omega)=Q / M$, where $Q$ is an aggregate index of input demand, yields $Y=M^{\frac{\nu}{\sigma-1}} Q$. If $\nu=0$, then $Y=Q$ and the number of available varieties is irrelevant for total output. This is the case discussed by Giavazzi and Blanchard (2003) or Egger and Kreickemeier (2007). ${ }^{6}$ If $\nu=1$, the production function takes the conventional Dixit-Stiglitz form, where an increased number of varieties increases total output.

Specification (1) offers at least three advantages. First, the recent estimates of Ardelean (2007) indicate that $\nu \in(0,1)$. Hence, the conventional formulation where $\nu=1$ tends to exaggerate the role of diversity for aggregate productivity. Second, if $\nu>0$, the autarky version of our model yields a counterfactual negative correlation between the unemployment rate and the labor supply. With trade and symmetric countries, this counterfactual implication is maintained on the world level. ${ }^{7}$ We nonetheless allow for $\nu>0$ to accommodate the dominant practice in the trade literature where gains from increased diversity are generally deemed important. Third, equation (1) with $\nu=1$ yields the cases discussed by Krugman (1980) or Melitz (2003) and thus allows us to address the importance of this assumption for their results.

The price index dual to (1) is $P=\left[M^{\nu-1} \int_{\omega \in \Omega} p(\omega)^{1-\sigma} d \omega\right]^{1 /(1-\sigma)}$, where $p(\omega)$ is the price

\footnotetext{
${ }^{6}$ Our formulation of the aggregate production is formally similar to the utility function employed by Corsetti, Martin, and Pesenti (2007) who also stress the role of $\nu$. Egger and Kreickemeier (2007) allow for $\nu \in[0,1]$ in the appendix of their paper. Benassy (1996) discusses how the welfare properties of the Krugman (1980) model depend on $\nu$. In particular, if $\nu \neq 1$, the decentralized equilibrium may yield over- or under-supply of input variety. This discussion carries over to the Melitz (2003) model.

${ }^{7}$ With heterogeneous countries and costly trade, larger countries suffer less from trade costs, have a higher level of aggregate productivity, and a lower rate of unemployment.
} 
of input $\omega$, inclusive of potential trade costs. We choose the final output good as the numéraire, i.e. $P=1$. Then the demand of intermediate inputs $\omega$ reads

$$
q(\omega)=\frac{Y}{M^{1-\nu}} p(\omega)^{-\sigma}
$$

Intermediate input producers. At the intermediate inputs level, there is a continuum of monopolistically competitive firms which produce each a unique variety. Labor is the unique factor of production. It is inelastically supplied by the household and enters firms' production functions linearly. Firms have different productivity levels $\varphi(\omega)$, so that output $q(\omega)=l(\omega) \varphi(\omega)$. In the following, we use $\varphi$ to index intermediate input producers.

On the domestic and on each of the $n$ symmetric export markets, input producers face fixed market access costs (e.g., distribution costs), $f_{D}$ and $f_{X}$ respectively. ${ }^{8}$ We assume that $\tau^{\sigma-1} f_{X}>f_{D}$. As explained below, this ensures that only a subset of firms export and that exporters are on average more efficient than non-exporting firms.

International trade is subject to the traditional variable iceberg trade $\operatorname{costs} \tau \geq 1$. In order to deliver a unit of input to a foreign market, the firm has to manufacture $\tau$ units. If it decides to serve both the domestic and the foreign markets, a firm allocates its output so as to maximize its total revenues. Operating revenues from sales on a given foreign market are therefore equal to $p_{X} q_{X} / \tau .{ }^{9}$ By symmetry, demands on the domestic and foreign markets are given by equation (2). Equating marginal revenues across markets therefore yields $p_{X}(\varphi)=\tau p_{D}(\varphi)$ and $q_{X}(\varphi)=$ $\tau^{1-\sigma} q_{D}(\varphi)$, where $D$ and $X$ denote the domestic and the export market. Hence, total revenues are given by

$$
R(l ; \varphi) \equiv\left[\frac{Y}{M^{1-\nu}}\left(1+I(\varphi) n \tau^{1-\sigma}\right)\right]^{1 / \sigma}(\varphi l)^{\frac{\sigma-1}{\sigma}},
$$

with $I(\varphi)$ being an indicator function that takes value one when a $\varphi$-firm exports and zero otherwise. Apart from the fact that their effective demand level is multiplied by $1+n \tau^{1-\sigma}$, exporting firms have similar revenue functions than non-exporting firms.

In order to facilitate the aggregation procedure, we define the average productivity level $\widetilde{\varphi}$ such that $q_{D}(\widetilde{\varphi})=Y / M^{\frac{\nu}{\sigma-1}+1}$. In the benchmark case where there are no externalities of scale, so that $\nu=0$, the domestic sales $q_{D}(\widetilde{\varphi})$ of the average firm is equal to the average sales per firm

\footnotetext{
${ }^{8}$ Since capital markets are perfect and uncertainty is resolved before market access costs are paid, $f_{X}$ and $f_{D}$ can be thought as flow fixed costs or - appropriately discounted - as upfront investment. In the latter case, whenever applicable, we use upper-case letters.

${ }^{9}$ Notice that $p_{X}$ is the c.i.f. price in the foreign market.
} 
$Y / M$, and the domestic price of its $\operatorname{good} p_{D}(\widetilde{\varphi})=P=1$.

Search frictions. The labor market is imperfectly competitive due to the existence of search frictions. Whereas marginal recruitment costs are increasing at the aggregate level because of congestion externalities, they are exogenous from a firm's point of view. The aggregate matching function is homogeneous of degree one so that the vacancy-unemployment ratio $\theta$ uniquely determines the rate $m(\theta)$ at which firms fill their vacancies. That rate is a decreasing function of $\theta$ and satisfies the following standard properties: $\lim _{\theta \rightarrow \infty} m(\theta)=0$ and $\lim _{\theta \rightarrow 0} m(\theta)=\infty$. Due to the linear homogeneity of the matching function, job seekers meet firms at the rate $\theta m(\theta)$ which is increasing in $\theta$. The cost of posting vacancies is proportional to the parameter $c$, so that recruiting $l$ workers entails spending $[c / m(\theta)] l$. In other words, firms face an adjustment cost function that is linear in labor.

\section{Labor Market Equilibrium}

This section characterizes the labor market equilibrium for two common models of wage determination, individual and collective bargaining. We establish that, in both cases, wages are constant across firms and the vacancy-unemployment ratio is increasing in aggregate productivity. In the subsequent analysis, we will index endogenous variables by the subscript $I$ or $C$ to indicate individual or collective bargaining. ${ }^{10}$

We devise our model in discrete time. All payments are made at the end of each period. Before the beginning of the next period, firms and workers are hit by idiosyncratic shocks: (i) with probability $\delta$, intermediate producers are forced to leave the market; (ii) with probability $\chi$, each job is destroyed because of match-specific shocks. We assume that these two shocks are independent so that $s=\delta+\chi-\delta \chi$ denotes the actual rate of job separation.

Unemployed workers earn a flow income of $b \Phi$, where $\Phi \equiv M^{\frac{\nu}{\sigma-1}} \tilde{\varphi}$ measures aggregate productivity (while-with some abuse of wording-we refer to $\tilde{\varphi}$ as average productivity). Indexing the value of non-market activity to $\Phi$ is consistent with the empirically relevant case where unemployment benefits are proportional to aggregate productivity. ${ }^{11}$ In any case, when $\nu=0$, setting the flow value of non-market activity equal to an exogenous constant does not affect

\footnotetext{
${ }^{10}$ We drop these indices when there is no risk of confusion.

${ }^{11}$ Directly indexing the value of non-market activity to wages, i.e. assuming that unemployed workers earn a flow income equal to $b w$ with $b<1$, yields similar results but slightly complicates the algebra.
} 
our main insights. On the other hand, when there are economies of scales $(\nu>0)$, it leads to multiple equilibria while our normalization ensures the existence of a unique equilibrium.

\subsection{Individual wage bargaining}

Individual wage bargaining involves the following sequence of actions: at each period, the intermediate input producer decides about the optimal number of vacancies $v_{I}$, taking the wage rate as given. The matching technology brings together the workers and the firm. Before production takes place, wages are bargained. Wage contracts are unenforceable: at any point in time, the firm may fire any employee and symmetrically any employee may quit. Solving the game by backward induction, we first characterize the firm's optimal vacancy setting behavior, and then solve the bargaining problem.

The market value of an intermediate producer solves

$$
\begin{aligned}
& J_{I}\left(l_{I} ; \varphi\right)=\max _{v_{I}} \frac{1}{1+r}\left\{R\left(l_{I} ; \varphi\right)-w_{I}\left(l_{I} ; \varphi\right) l_{I}-c v_{I}-f_{D}-I(\varphi) n f_{X}+(1-\delta) J_{I}\left(l_{I}^{\prime} ; \varphi\right)\right\}, \\
& \text { s.t. }(i) R\left(l_{I} ; \varphi\right)=\left[\frac{Y}{M^{\nu-1}}\left(1+I(\varphi) n \tau^{1-\sigma}\right)\right]^{1 / \sigma}\left(\varphi l_{I}\right)^{\frac{\sigma-1}{\sigma}}, \\
& \text { (ii) } l_{I}^{\prime}=(1-\chi) l_{I}+m\left(\theta_{I}\right) v_{I},
\end{aligned}
$$

where $l_{I}^{\prime}$ is the level of employment next period, and the dependence of $l_{I}, v_{I}$ and $q_{I}$ on $\varphi$ is understood. Constraint $(i)$ is the revenue function (3) and (ii) gives the law of motion of employment at the firm level. The first order condition for vacancy posting reads

$$
\frac{c}{m\left(\theta_{I}\right)}=(1-\delta) \frac{\partial J_{I}\left(l_{I}^{\prime}, \varphi\right)}{\partial l_{I}^{\prime}}
$$

so that the firm sets the shadow value of labor equal to the marginal recruitment cost. Substituting the constraints into the objective function of the firm, differentiating with respect to $l_{I}$, and using the optimality condition (5) yields

$$
\frac{\partial J_{I}\left(l_{I}, \varphi\right)}{\partial l_{I}}=\frac{1}{1+r}\left[\frac{\partial R\left(l_{I} ; \varphi\right)}{\partial l_{I}}-w_{I}\left(l_{I}, \varphi\right)-\frac{\partial w_{I}\left(l_{I}, \varphi\right)}{\partial l_{I}} l_{I}+\frac{c}{m\left(\theta_{I}\right)}(1-\chi)\right] .
$$

The firm acts as a monopsonist by taking into account the effect of additional employment on the wage of inframarginal employees. Replacing the first order condition (5) on the left-hand side of (6), we obtain an expression that implicitly determines the optimal pricing behavior of the monopolist

$$
\frac{\partial R\left(l_{I} ; \varphi\right)}{\partial l_{I}}=w_{I}\left(l_{I}, \varphi\right)+\frac{\partial w_{I}\left(l_{I}, \varphi\right)}{\partial l_{I}} l_{I}+\frac{c}{m\left(\theta_{I}\right)}\left(\frac{r+s}{1-\delta}\right) .
$$


This expression differs from Melitz (2003) in that marginal costs are augmented by a monopsony effect and expected recruitment costs.

The total surplus accruing from a successful match is split between the employee and the firm. The worker's surplus is equal to the difference between the value of being employed $E_{I}(l ; \varphi)$ by a firm with productivity $\varphi$ and workforce $l$ and the value of being unemployed $U_{I}$. The firm's surplus is simply equal to the marginal increase in the firm's value $\partial J_{I}(l ; \varphi) / \partial l_{I}$ because individual bargaining implies that each employee is treated as the marginal worker. Following Stole and Zwiebel (1996) we assume that the outcome of bargaining over the division of the total surplus from the match satisfies the following "surplus-splitting" rule

$$
(1-\beta)\left[E_{I}(l ; \varphi)-U_{I}\right]=\beta \frac{\partial J_{I}(l ; \varphi)}{\partial l_{I}},
$$

where the parameter $\beta$ measures the bargaining power of the worker and thus belongs to $(0,1)$.

As explained by Stole and Zwiebel (1996), condition (8) can be micro-founded either by cooperative or non-cooperative game theory. In the non-cooperative case, condition (8) characterizes the unique subgame perfect equilibrium of an extensive form game where the firm and its employees play a bargaining game of Binmore et al. (1986) within each bargaining session. Accordingly, neither the firm nor any employee can improve their positions by renegotiating. In the cooperative case, condition (8) assigns to each party its Shapley value, that is the average, over all possible permutations, of each player contribution to possible coalitions ordered below him. ${ }^{12}$ When $\beta$ differs from $1 / 2$, condition (8) generalizes the symmetric Shapley value to situations where players are not treated identically.

Using the shadow value of labor (6) in the bargaining solution (8), we obtain a differential equation in the wage rate, which can be solved to give rise to a Wage curve $\left(W_{I}\right)$. The equilibrium wage and labor market tightness are found by interacting $W_{I}$ with a Job Creation curve $\left(J C_{I}\right)$, as in standard search-matching models.

Proposition 1 When wages are bargained at the individual level, the labor market admits an equilibrium if and only if $b<\frac{\sigma-1}{\sigma-\beta}$. The equilibrium is unique and such that wages are constant across firms. The equilibrium wage, $w_{I}$, and vacancy-unemployment ratio, $\theta_{I}$, simultaneously

\footnotetext{
${ }^{12}$ This interpretation is the one favored by Helpman and Itskhoki (2007).
} 
satisfy the following Wage and Job Creation conditions:

$$
\begin{aligned}
W_{I}: & w_{I}=b \Phi+\frac{\beta}{1-\beta}\left(\frac{c}{m\left(\theta_{I}\right)}\left(\frac{r+s}{1-\delta}\right)\right)+\frac{\beta}{1-\beta} \frac{c \theta_{I}}{1-\delta} \\
J C_{I}: & w_{I}=\left(\frac{\sigma-1}{\sigma-\beta}\right) \Phi-\frac{c}{m\left(\theta_{I}\right)}\left(\frac{r+s}{1-\delta}\right)
\end{aligned}
$$

The Job Creation curve characterizes firms' optimal recruitment efforts which are, as expected, decreasing in the wage level. The Wage curve implies that wages depend only on aggregate productivity so that workers are paid similarly across firms with different productivity levels. This somewhat surprising result extends to a dynamic setting the proof of Stole and Zwiebel (1996) that firms exploit their monopsony power until employees are paid their outside option. In our case, the outside option is augmented by the recruitment costs that the firm would have to pay if it were to replace the worker. Quite intuitively, the workers' bargaining position is improving in the severity of labor market frictions which explains why the Wage curve is increasing in $\theta$.

The existence condition in Proposition 1 states that the flow value of non-market activity should not yield revenues in excess of a share $(\sigma-1) /(\sigma-\beta)$ of aggregate productivity. For values of $\sigma$ above 2 and bargaining power $\beta$ close or below $1 / 2$, as commonly assumed in the literature, this implies that the flow value of non-market activity is no larger than $2 / 3$ aggregate productivity; this is a rather undemanding requirement.

Figure 1 illustrates the effect of an increase in aggregate productivity $\Phi$ on labor market tightness. The Job Creation curve shifts upwards (from the solid to the dashed curve) because firms are on average more productive and search more intensively for workers. The intercept of the Wage curve also increases because unemployment benefits are proportional to aggregate productivity. However, this second effect is dominated because the flow value of non-market activity is only equal to a share $b<1$ of market productivity. ${ }^{13}$ Hence labor market tightness goes from $\theta_{I}^{0}$ to $\theta_{I}^{1}$. Trade liberalization will affect labor market outcomes to the extent that it changes aggregate productivity $\Phi$ by modifying the degree of input diversity $M$ and/or the average productivity of input producers $\tilde{\varphi}$.

Corollary 1 When wages are bargained at the individual level, the vacancy-unemployment ratio $\theta_{I}$ is increasing in aggregate productivity $\Phi$.

\footnotetext{
${ }^{13}$ When the flow value of non-market activity is simply set equal to an exogenous constant, the Wage curve is not affected by a change in $\Phi_{I}$. Then the result in Corollary 1 follows immediately.
} 


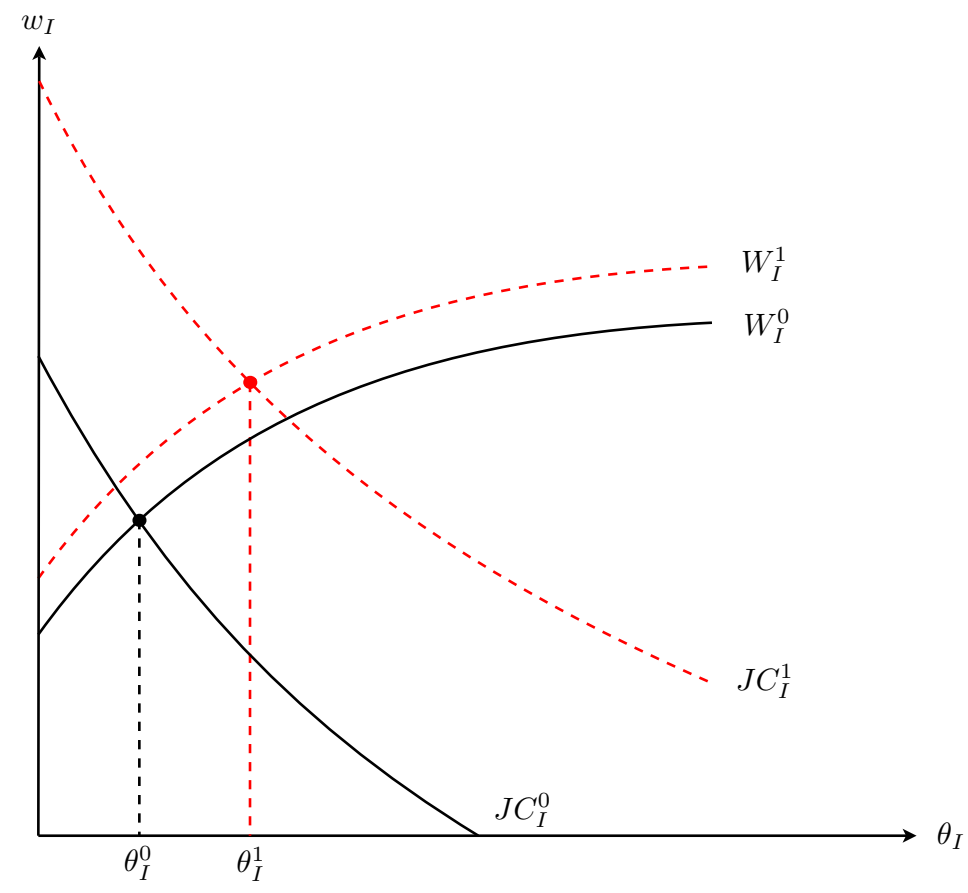

Figure 1: Effect of an increasing $\Phi_{I}$ in the Individual Bargaining regime.

\subsection{Collective bargaining}

In a firm covered by collective bargaining, workers form a firm-wide coalition, that is, a trade union. When bargaining fails and workers go on strike, the firm loses not only the value associated to the marginal worker, as with individual bargaining, but its entire labor force. We opt for an efficient bargaining setup so that the firm and the union bargain about both wages and employment. This ensures that we are considering equilibria lying on the Pareto frontier. ${ }^{14}$

Negotiations between the union and the firm take place in the first period. ${ }^{15}$ The union's objective is the expected sum of its members' rents

$$
\mathbf{U}(l, w) \equiv(1-\delta) l\left[\frac{w-r U}{r+\delta}\right]
$$

\footnotetext{
${ }^{14}$ Our main results also hold in a right to manage set-up where unions negotiate only about wages and firms have full freedom to set the level of employment. Barth and Zweimüller (1995) study different wage bargaining scenarios when firms are heterogeneous with respect to their productivity.

${ }^{15}$ One could instead consider that the firm and the union bargain on the steady-state profits, so that $\mathbf{F}(l, w ; \varphi)=$ $\left(\frac{1-\delta}{r+\delta}\right)\left[R(l ; \varphi)-w l(\varphi)-\frac{c}{m(\theta)} \chi l(\varphi)\right]$. This obviously generates a hold-up problem where the union does not take into account the initial recruitment costs. Then employment is lower and wages higher but the main insights of this section are not fundamentally modified.
} 
while the firm seeks to maximize its expected variable profits

$$
\mathbf{F}(l, w ; \varphi) \equiv\left(\frac{1-\delta}{r+\delta}\right)\left[R(l ; \varphi)-w l(\varphi)-\frac{c}{m(\theta)} \chi l(\varphi)\right]-\frac{c}{m\left(\theta_{C}\right)} l .
$$

The negotiation specifies both employment and wages. The solution lies on the contract curve which connects the points where the firm iso-profit curves are tangent to the union indifference curves. The actual agreement is pinned down by the union's bargaining power $\beta$. Proposition 2 shows that the labor market equilibrium can be characterized in a similar fashion than in the Individual Bargaining regime.

Proposition 2 When wages are collectively bargained, the labor market admits an equilibrium if and only if $b<(\sigma-1) / \sigma$. The equilibrium is unique and such that wages are constant across firms. The equilibrium wage, $w_{C}$, and vacancy-unemployment ratio, $\theta_{C}$, simultaneously satisfy the following Wage and Job Creation conditions:

$$
\begin{aligned}
W_{C}: & w_{C}=b \Phi+\frac{\beta}{\sigma}\left(\frac{\theta_{C} m\left(\theta_{C}\right)}{r+s}\right) \Phi+\frac{\beta}{\sigma} \Phi \\
J C_{C}: & w_{C}=\left(1-\frac{1-\beta}{\sigma}\right) \Phi-\frac{c}{m\left(\theta_{C}\right)}\left(\frac{r+s}{1-\delta}\right)
\end{aligned}
$$

For the same reasons than before, the Wage curve is increasing in $\theta$ while the Job Creation curve is decreasing. The bargained wage is equal to the opportunity cost of employment $r U_{C}$ plus a share $\beta$ of the remaining profits per worker. Due to the existence of rent-sharing, and in contrast to individual bargaining, the slope of the Wage curve is increasing in aggregate productivity. Yet, as with individual bargaining, the wage rate is the same across firms with different levels of productivity. Figure 2 illustrates why, in our CES setting, differences in idiosyncratic productivity wash out so that there is no wage dispersion.

First consider the curves without dot. The plain curve plots the average revenues per worker while the dashed curve plots the marginal revenues. The competitive outcome where $\beta=0$ is obviously given by the point where the marginal revenue function intersects the workers' outside option $r U_{C}$. Starting from this point, the contract curve describes a vertical ${ }^{16}$ segment which reaches the average revenue function. This upper-bound gives the outcome when workers have all the bargaining power $(\beta=1)$ since then the firm's profits net of fixed costs are zero. When $\beta$ varies between 0 and 1 , wages fluctuate between these two extremes. Now consider the problem

\footnotetext{
${ }^{16}$ As usual, the verticality of the contract curve follows from the risk neutrality of workers. Introducing risk aversion yields a contract curve with a positive but bounded slope.
} 


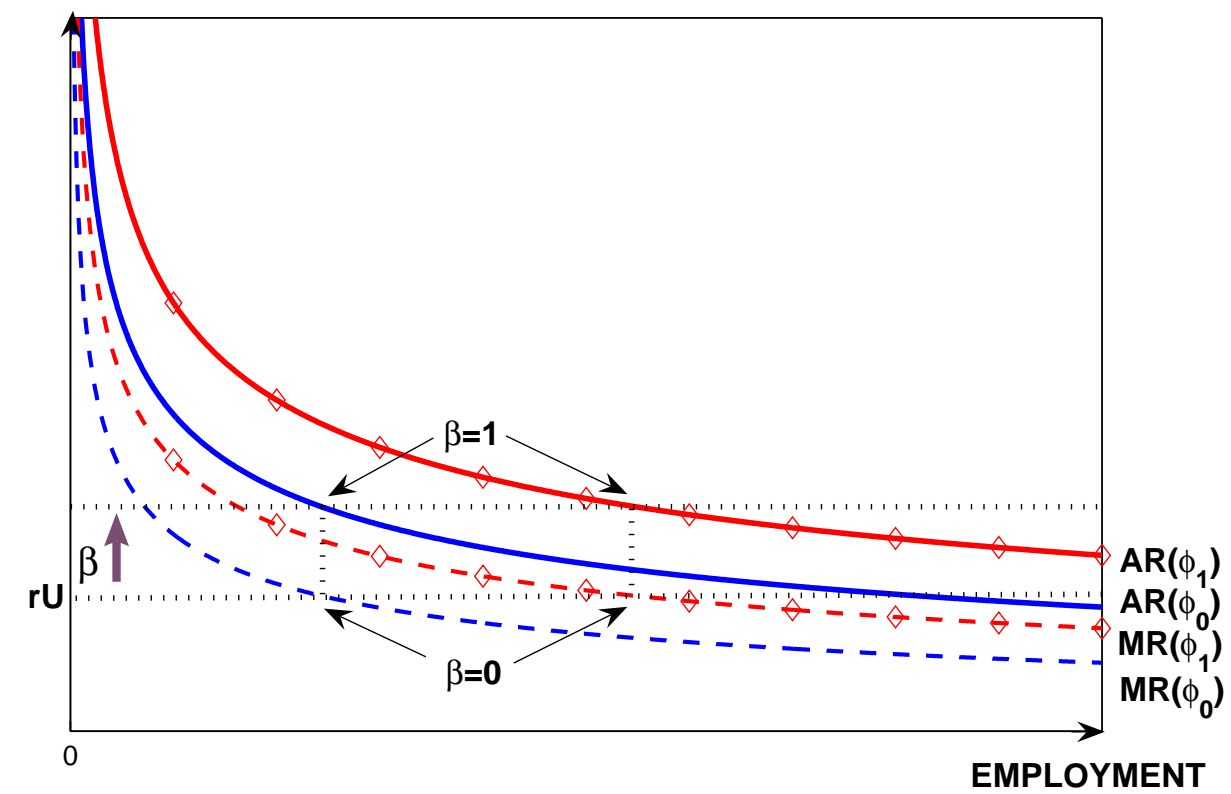

Figure 2: Collective bargaining with $\varphi_{0}<\varphi_{1}$.

of a firm with a higher productivity $\varphi_{1}>\varphi_{0}$. As shown by the dotted curves, the only difference is that both average and marginal revenues functions are shifted to the right. Furthermore, since firms apply the same mark-up, the two curves are shifted parallely. Accordingly, firms with a higher productivity hire more workers but pay the same wage.

The most significant difference with the individual bargaining regime is that now aggregate productivity $\Phi$ also raises the slope of the Wage curve. Yet, as stated in Corollary 2, this additional effect on the Wage curve is again unambiguously dominated by the shift of the Job Creation curve.

Corollary 2 When wages are collectively bargained, the vacancy-unemployment ratio $\theta_{C}$ is increasing in aggregate productivity $\Phi$.

We would like to acknowledge an important caveat before closing our characterization of the labor market: if search costs $c$ were measured in units of labor, then increasing $\Phi$ would raise the real wage but leave the labor market tightness unchanged. ${ }^{17}$ This illustrates that changes

${ }^{17}$ Similarly, if $c$ were indexed to aggregate productivity (e.g. $c=\Phi \bar{c}$, with $\bar{c}>0$ ) the equilibrium value of $\theta$ 
in employment are driven by the negative effect of aggregate productivity on real vacancy costs. For two reasons we stick to the assumption that vacancy costs are measured in units of the final output good. First, as soon as search costs depend on the price of the final output good (e.g. $c=w \bar{c}+\underline{c}$, with $\{\bar{c}, \underline{c}\} \subset \mathbb{R}_{+}^{2}$ ), variations in $\Phi$ do affect $\theta$ so that Corollaries 1 and 2 continue to hold. Second, it is not clear how to model wage bargaining when the cost of a vacancy is itself subject to negotiation, as it would be the case if the production of search services were to draw on labor. We therefore stick to the conventional practice and assume that the search process does not directly require the use of labor. ${ }^{18}$

In this section, we have described how to solve for the labor market equilibrium. Our two equilibrium conditions take the average productivity, $\tilde{\varphi}$, and the equilibrium diversity of inputs, $M$, as given. Changes in these two variables affect aggregate productivity $\Phi$, thereby moving the Job Creation and Wage curves. To the extent that $\Phi$ goes up, the rate of unemployment falls and the real wage rises, regardless of the bargaining regime. The next section explains how to endogenize average productivity.

\section{$4 \quad$ Firm Entry and Exit}

We model firm entry and exit in a similar fashion than Melitz (2003), which in turn draws on the seminal work by Hopenhayn (1992). We deliberately keep the analysis as brief as possible and refer the reader to Melitz' paper for further details. Our contribution is to show that the equilibrium level of average productivity $\tilde{\varphi}$ and the labor market tightness $\theta$ are independent (hence we drop subindices $\{I, C\}$ from the outset).

The entry process is in two stages. First, prospective entrants pay an entry cost $F_{E}$. Only after entering are they able to draw their productivity from a sampling distribution with c.d.f. $G(\varphi)$ and p.d.f. $g(\varphi)$. After the draw, productivities remain constant over time. ${ }^{19}$ Given that firms' revenues are increasing in $\varphi$, one can define a threshold $\varphi_{D}^{*}$ below which firms do not take up production. Similarly, firms with a productivity level between $\varphi_{D}^{*}$ and $\varphi_{X}^{*}$ will serve only their domestic market. The share of exporting firms is therefore equal to $\varrho \equiv$ $\left[1-G\left(\varphi_{X}^{*}\right)\right] /\left[1-G\left(\varphi_{D}^{*}\right)\right]$. The average level of productivity of intermediate input producers would be independent from $\Phi$.

${ }^{18}$ Note that, if aggregate TFP were trending, our model would always exhibit a balanced growth path, regardless of whether we index $c$ to $\Phi, w$ or to the final output good.

${ }^{19}$ This stylized assumption is made mainly for tractability reasons. It is the key difference between Melitz's (2003) and Hopenhayn's (1992) models, as the latter also allows firms' productivities to vary over time. 
is given by the following weighted sum

$$
\tilde{\varphi}=\left\{\frac{1}{1+n \varrho}\left[\tilde{\varphi}_{D}^{\sigma-1}+n \varrho\left(\frac{\tilde{\varphi}_{X}}{\tau}\right)^{\sigma-1}\right]\right\}^{\frac{1}{\sigma-1}}
$$

where $\tilde{\varphi}_{D}$ and $\tilde{\varphi}_{X}$ are average productivity indices for the populations of firms that sell only domestically and that also sell abroad

$$
\tilde{\varphi}\left(\varphi_{D}^{*}\right)=\left[\frac{\int_{\varphi_{D}^{*}}^{+\infty} \varphi^{\sigma-1} g(\varphi) d \varphi}{1-G\left(\varphi_{D}^{*}\right)}\right]^{\frac{1}{\sigma-1}} \text { and } \tilde{\varphi}\left(\varphi_{X}^{*}\right)=\left[\frac{\int_{\varphi_{X}^{*}}^{+\infty} \varphi^{\sigma-1} g(\varphi) d \varphi}{1-G\left(\varphi_{X}^{*}\right)}\right]^{\frac{1}{\sigma-1}} \text {. }
$$

Let us first characterize the entry threshold $\varphi_{D}^{*}$. The linearity of the adjustment cost function implies that firms reach their optimal size by the end of their first period of activity. ${ }^{20}$ It is profitable to start operating and to recruit workers when

$$
(1-\delta) \sum_{t=0}^{\infty}(1-r-\delta)^{t} \pi_{D}(\varphi)-\frac{c}{m(\theta)} l_{D}(\varphi)-f_{D}=(1-\delta) \frac{\pi_{D}(\varphi)}{r+\delta}-\frac{c}{m(\theta)} l_{D}(\varphi)-f_{D} \geq 0
$$

where

$$
\pi_{D}(\varphi)=p_{D}(\varphi) \varphi l_{D}(\varphi)-w l_{D}(\varphi)-\frac{c}{m(\theta)} \chi l_{D}(\varphi)-f_{D}
$$

is the optimal flow profit from domestic sales of a $\varphi$-firm. Condition (15) accounts for the fact that firms pay market access and vacancy costs up front but have to wait one period to recruit their workers. In this period, they can be hit by a destruction shock, so that, with probability $\delta$, they never start producing. The cut-off productivity $\varphi_{D}^{*}$ is such that the weak inequality in (15) binds. The proportionality of domestic prices allows us to relate operating profits of the marginal and average firm

$$
\frac{\pi_{D}\left(\tilde{\varphi}_{D}\right)+f_{D}}{\pi_{D}\left(\varphi_{D}^{*}\right)+f_{D}}=\frac{l_{D}\left(\tilde{\varphi}_{D}\right)}{l_{D}\left(\varphi_{D}^{*}\right)}=\left(\frac{\tilde{\varphi}_{D}}{\varphi_{D}^{*}}\right)^{\sigma-1}
$$

Hence, (15) is equivalent to the following Zero Cutoff Profit condition

$$
\pi_{D}\left(\tilde{\varphi}_{D}\right)=\left(\frac{r+\delta}{1-\delta}\right)\left[\frac{c}{m(\theta)} l_{D}\left(\tilde{\varphi}_{D}\right)\right]+f_{D}\left[\left(\frac{\tilde{\varphi}_{D}}{\varphi_{D}^{*}}\right)^{\sigma-1}\left(\frac{1+r}{1-\delta}\right)-1\right] .
$$

\footnotetext{
${ }^{20}$ Gradual convergence can be restored either by considering that recruitment costs are convex in the number of posted vacancies, as in Bertola and Caballero (1994), or by assuming that firms can post only one vacancy, as in Acemoglu and Hawkins (2007). Since this greatly complicates the aggregation procedure, we adopt a more parsimonious specification where, as in Melitz (2003), firms jump to their optimal size. See Koeniger and Prat (2007) for a numerical analysis of a model with firm entry and convex adjustment costs.
} 
The choice of exporting status can be characterized in a similar fashion. One simply has to replace the subscripts $D$ in equation (15) by $X$ and to update the definition of profits as follows

$$
\pi_{X}(\varphi)=p_{X}(\varphi) \varphi l_{X}(\varphi) / \tau-w l_{X}(\varphi)-\frac{c}{m(\theta)} \chi l_{X}(\varphi)-f_{X}
$$

Given that export prices are also proportional to productivity, we obtain a similar Zero Cutoff Profit (ZCP) condition for exporting firms

$$
\pi_{X}\left(\tilde{\varphi}_{X}\right)=\left(\frac{r+\delta}{1-\delta}\right)\left[\frac{c}{m(\theta)} l_{X}\left(\tilde{\varphi}_{X}\right)\right]+f_{X}\left[\left(\frac{\tilde{\varphi}_{X}}{\varphi_{X}^{*}}\right)^{\sigma-1}\left(\frac{1+r}{1-\delta}\right)-1\right] .
$$

To see that some firms serve solely their domestic market, notice that $R_{X}(\varphi)=p_{X}(\varphi) q_{X}(\varphi) / \tau=$ $\tau^{1-\sigma} R_{D}(\varphi)$ and $l_{X}(\varphi)=\tau^{1-\sigma} l_{D}(\varphi)$. Accordingly, the flow profits satisfy $\pi_{X}(\varphi)=\tau^{1-\sigma}\left[\pi_{D}(\varphi)+\right.$ $\left.f_{D}\right]-f_{X}$. Replacing this expression in (15) illustrates that a $\varphi_{D}^{*}$-firm does not find it profitable to incur the exporting costs when, as assumed in Section $2, \tau^{\sigma-1} f_{X}>f_{D} \cdot{ }^{21}$

The ZCP conditions characterize the optimal decision of a firm who knows its idiosyncratic productivity. Free Entry (FE) allows us to take into account the behavior of prospective entrants. Entry occurs until expected profits are equal to the entry cost $F_{E}$, so that

$\frac{F_{E}}{1-G\left(\varphi_{D}^{*}\right)}=\frac{\pi_{D}\left(\tilde{\varphi}_{D}\right)}{r+\delta}(1-\delta)-\frac{c}{m(\theta)} l_{D}\left(\tilde{\varphi}_{D}\right)-f_{D}+n \varrho\left[\frac{\pi_{X}\left(\tilde{\varphi}_{X}\right)}{r+\delta}(1-\delta)-\frac{c}{m(\theta)} l_{X}\left(\tilde{\varphi}_{X}\right)-f_{X}\right]$.

Free entry holds when this equality is satisfied because an entrant will start to operate with probability $1-G\left(\varphi_{D}^{*}\right)$. On the domestic market, successful entrants earn an average expected stream of profits equal to equation (15) as evaluated for the representative firm $\tilde{\varphi}_{D}$. Moreover, entrants will also export with probability $1-G\left(\varphi_{X}^{*}\right)=\varrho\left[1-G\left(\varphi_{D}^{*}\right)\right]$ and earn the average expected stream of profits on the export markets. Taking into account these two eventualities leads to equation (18). Combining the FE and ZCP Conditions yields

$$
F_{E}=\left[1-G\left(\varphi_{D}^{*}\right)\right]\left(\frac{1+r}{r+\delta}\right)\left\{f_{D}\left[\left(\frac{\tilde{\varphi}\left(\varphi_{D}^{*}\right)}{\varphi_{D}^{*}}\right)^{\sigma-1}-1\right]+n \varrho f_{X}\left[\left(\frac{\tilde{\varphi}\left(\varphi_{X}^{*}\right)}{\varphi_{X}^{*}}\right)^{\sigma-1}-1\right]\right\}
$$

Although (19) depends on both $\varphi_{D}^{*}$ and $\varphi_{X}^{*}$, it actually pins down the two variables because $\varphi_{X}^{*}=\varphi_{D}^{*} \tau\left(f_{X} / f_{D}\right)^{\frac{1}{\sigma-1}} \cdot{ }^{22}$ Given that our equilibrium condition is the same than in Melitz

\footnotetext{
${ }^{21}$ When this partitioning does not hold, one cannot use equation (15) to determine whether or not a firm operates on the domestic market because it may be optimal to pay the fixed operating cost $f_{X}$ in order to access the export markets.

${ }^{22}$ See the proof of Lemma 1 for a derivation of this equality.
} 
(2003), the existence and uniqueness of the equilibrium in the product market are ensured. Most interestingly, the vacancy-unemployment ratio $\theta$ drops out when the FE and ZCP Conditions are interacted. This implies that, as stated in the following lemma, the entry and export thresholds depend solely on the product market parameters $\left\{F_{E}, f_{D}, f_{X}, n, \tau, \sigma, r, \delta\right\}$ and the properties of the c.d.f. $G(\varphi)$.

Lemma 1 (Separability) Regardless of the bargaining regime, the equilibrium average productivity of intermediate producers, $\tilde{\varphi}$, does not depend on the vacancy-unemployment ratio $\theta$ or on input diversity $M$.

In other words, labor market conditions do not influence the optimal partitioning of firms. Note that this is a general feature of the Melitz (2003) framework when firms pay identical wages. To understand this result, it is useful to remember that the FE and ZCP conditions relate the average profit per firm to the cutoff productivity. Hence, they are not affected by the impact on operating revenues of changes in labor market tightness and wages. Firms' equilibrium sizes adjust so as to offset any increase or decrease in revenues per worker until both product market conditions are satisfied again.

Accordingly, the only relevant effect is the positive relationship between $\theta$ and the initial recruitment costs, $\operatorname{cl}(\varphi) / m(\theta)$, of newly created firms. On the one hand, higher recruitment costs discourage potential entrants. For a given level of operating profits, free entry requires a greater likelihood of entering the market, that is a lower cutoff productivity $\varphi^{*}$. On the other hand, firms that have already paid the entry cost and have drawn their idiosyncratic productivity find it less attractive to initiate production when recruitment costs are higher. This obviously raises the cutoff productivity $\varphi^{*}$. Given that the expected recruitment costs before entry are equal to the recruitment costs of the average firm, the ex-ante and ex-post effects of $\theta$ exactly offset each other. ${ }^{23}$ Plotting, as Melitz (2003) does, the equilibrium conditions in the cutoffproductivity / average-profit space yields the following adjustments: following an increase in $\theta$, both FE and ZCP loci shift up by the same amount so that the average profit per firm goes up, but the cutoff productivity remains constant.

The separability property stated in Lemma 1 allows to solve for equilibrium in a recursive way. Average productivity and cutoff productivities can be determined as in Melitz (2003) by considering solely product market parameters. Taking these values as given, we can then solve

\footnotetext{
${ }^{23}$ This property hinges on the $\log$-linearity of firm sizes with respect to $\varphi$. Hence, the independence of $\varphi^{*}$ on $\theta$ clearly depends on the CES specification.
} 
for the equilibrium in the labor market. Note, however, that we still need to determine input diversity $M$ in order to derive aggregate productivity $\Phi$. As shown in the next section, this last step is trivial when there are no economies of scale but otherwise leads to the introduction of an additional equilibrium condition.

\section{Unemployment and Trade Liberalization}

This section discusses three globalization scenarios: $(i)$ a reduction of variable trade costs, $(i i)$ an increase in the number of trade relations and (iii) a drop in the fixed foreign distribution costs $f_{X}$. The first and the third scenario capture technological (transportation costs) and political (tariffs, technical barriers to trade) change, while the second addresses the emergence of new countries into the global trading system. We describe the interaction of trade liberalization and unemployment in two steps. First, we consider the case where trade affects aggregate outcomes through the selection effect only $(\nu=0)$. This isolates the novel mechanism introduced by Melitz (2003) and characterizes a particularly tractable special case. Then we analyze the more intricate case where trade also affects outcomes through an external scale effect, as in Krugman (1980) and in much of the subsequent literature.

\subsection{The equilibrium rate of unemployment}

The steady-state rate of unemployment is linked to the degree of labor market tightness $\theta$ and the importance of labor market churning, as captured by $s$, via the standard Beveridge curve

$$
u(\theta)=\frac{s}{s+\theta m(\theta)} .
$$

This condition ensures that the flows in and out of the unemployment pool are equal. As in standard search-matching models, the rate of unemployment is a decreasing function of the vacancy-unemployment ratio. Since we have shown in Propositions 1 and 2 that $\theta$ is increasing in the level of aggregate productivity, it is sufficient to know how trade affects $\Phi \equiv M^{\frac{\nu}{\sigma-1}} \tilde{\varphi}$ in order to characterize its impact on employment.

As usual, the equilibrium mass of firms is such that the labor market clears. Given that all workers are employed by domestic firms

$$
M_{D}\left[l_{D}\left(\tilde{\varphi}_{D}\right)+n \varrho l_{X}\left(\tilde{\varphi}_{X}\right)\right]=[1-u(\theta)] L
$$


where $L$ is the size of the labor force and $M_{D}$ is the mass of domestic producers in each country. Due to imports from foreign firms, input diversity $M$ (i.e., the number of available varieties) is higher and equal to $M=M_{D}(1+n \varrho)$.

Lemma 2 Equilibrium input diversity is determined by the Labor Market Clearing (LMC) condition which is a function of labor market tightness $\theta$ and average productivity $\tilde{\varphi}$. For individual bargaining, the $L M C$ reads

$L M C_{I}: M_{I}\left(\theta_{I}\right)=\left[(1+n \varrho)\left(1-u\left(\theta_{I}\right)\right) L\left(\frac{1-\beta}{\sigma-\beta}\right)\left(\frac{1-\delta}{r+s}\right)\left(\frac{\tilde{\varphi}}{\left(\frac{r+\delta}{1+r}\right) \frac{F_{E}}{1-G\left(\varphi_{D}^{*}\right)}+f_{D}+n \varrho f_{X}}\right)\right]^{\frac{\sigma-1}{\sigma-1-\nu}}$.

For collective bargaining, the LMC is given by

$L M C_{C}: M_{C}\left(\theta_{C}\right)=\left[(1+n \varrho)\left(1-u\left(\theta_{C}\right)\right) L\left(\frac{1-\beta}{\sigma}\right)\left(\frac{1-\delta}{r+s}\right)\left(\frac{\tilde{\varphi}}{\left(\frac{r+\delta}{1+r}\right) \frac{F_{E}}{1-G\left(\varphi_{D}^{*}\right)}+f_{D}+n \varrho f_{X}}\right)\right]^{\frac{\sigma-1}{\sigma-1-\nu}}$.

Surprisingly enough, the sign of the relationship between input diversity $M$ and aggregate employment is not always positive. This is because $M$ has two opposite effects: (i) at the aggregate level, a larger number of firms naturally increases the number of employees; (ii) at the firm level, economies of scale implies that more input diversity raises revenues per worker so that firms have to be smaller for the ZCP condition to be satisfied.

When $\nu=0$, the scale effect is ruled out and so $M$ is always increasing in the level of employment, as one might expect. On the other hand, when $\sigma<\nu+1$, so that firms enjoy strong market power and economies of scale are significant, $M$ is decreasing in aggregate employment because the effect at the firm level dominates. Given that empirical studies typically yield estimates for $\sigma$ above 2 and for $\nu$ in the interval $(0,1)$, we restrict our attention to cases where $\sigma>\nu+1 .{ }^{24}$ In this case, the LMCs define upward-sloping loci because employment is increasing in $\theta$ so that labor market clearing requires the mass of producer to be larger.

\footnotetext{
${ }^{24}$ Egger and Kreickemeier (2007) also impose a similar restriction in order to ensure that their equilibrium is stable. Note that the condition $\sigma<\nu+1$ implies that the elasticity of aggregate productivity $\Phi$ with respect to input diversity $M$ is smaller than unity.
} 


\subsection{Trade and unemployment without external economies of scale}

In the absence of external economies of scale, i.e. when $\nu=0$, average and aggregate productivity coincide since input diversity drops out from the description of the labor market equilibrium. It is therefore sufficient to see how average productivity, $\tilde{\varphi}$, changes in our globalization scenarios. Trade affects the distribution of productivities across intermediate input producers by reallocating labor towards exporters and away from purely domestic firms, both at the extensive and at the intensive margin. The effect of trade liberalization on average productivity is nevertheless ambiguous because $\tilde{\varphi}$ factors in the output loss in export transit.

Part (i) of the following proposition gives a sufficient condition under which some liberalization scenarios always lead to an increase in aggregate employment. Part (ii) derives necessary and sufficient conditions for the case where the productivity distribution $G(\varphi)$ belongs to the Pareto family of distributions, as usually done in the literature on heterogeneous firms. ${ }^{25}$

Proposition 3 Assume that there are no economies of scale $(\nu=0)$ and that the conditions stated in Propositions 1 and 2 are met.

(i) If $f_{X} \geq f_{D}$, a reduction of variable trade costs $\tau$ or an increase in the number of trading partners $n$ lead to a fall in the equilibrium rate of unemployment and a rise in the real wage, regardless of whether wages are bargained individually or collectively. A fall in fixed foreign distribution costs has an ambiguous effect on labor market outcomes.

(ii) Let firms draw their productivities from a Pareto distribution with dispersion parameter $\gamma$ such that $\gamma>\sigma-1$. Then, regardless of the wage bargaining regime, the equilibrium rate of unemployment falls and the real wage rises

(a) due to a reduction in $\tau$ or an increase in $n$ if and only if $\frac{\sigma-1}{\gamma}\left(1+n \tau^{-\gamma}\left(f_{D} / f_{X}\right)^{\frac{\gamma}{\sigma-1}}\right) \geq$ $\frac{f_{D}}{f_{X}}-1$,

(b) and due to a reduction in $f_{X}$ if and only if $\frac{\gamma^{2}}{(\sigma-1)^{2}} \geq \frac{f_{X}}{f_{X}-f_{D}}\left[1+n \tau^{-\gamma}\left(\frac{f_{D}}{f_{X}}\right)^{\frac{\gamma}{\sigma-1}}\right]$.

The new insight in Melitz (2003) is that trade liberalization reallocates market shares towards efficient firms. Exporters, however, also incur iceberg transport costs which have to be deducted from the productivity gains at the factory gate. Whether or not trade liberalization enhances average productivity depends on which of these two adjustments prevails. ${ }^{26}$ When $f_{X}>f_{D}$,

\footnotetext{
${ }^{25}$ See Egger and Kreickemeier, 2007; Bernard, Redding, Schott, 2007; Helpman, Melitz, Yeaple, 2004.

${ }^{26}$ Melitz (2003) briefly alludes to the ambiguity of the relationship between trade liberalization and $\tilde{\varphi}$ (see footnote 26, page 1713). He also introduces a measure of productivity at the factory gate and shows that it is always lower in autarky.
} 
revenues generated on each foreign market have to exceed domestic revenues. In other words, the higher efficiency of exporting firms offsets both transport costs and the difference between $f_{X}$ and $f_{D}$. This is why the selection effect always dominates the losses in export transit. On the other hand, when $f_{X}<f_{D}$, some of the transport costs are compensated by lower fixed costs in foreign markets. Then the productivity gains at the factory gate due to trade liberalization are not necessarily higher than the increase in export losses.

A reduction in fixed costs of export $f_{X}$ triggers similar adjustments than a decrease in $\tau$ : it raises the domestic threshold $\varphi_{D}^{*}$ and lowers the export threshold $\varphi_{X}^{*}$. Yet, it reallocates market shares in a different way. Whereas a decrease in $\tau$ raises the combined market shares of firms that already exported prior to liberalization, a decrease in $f_{X}$ only benefits new exporters which are, on average, less productive than existing ones. Hence, the overall effect on average productivity is ambiguous and depends on whether the new exporters are on average more productive than the economy-wide average before the fall in $f_{X}$.

The region where the relationship between trade openness and average productivity is negative depends on the other parameters of the model. It can be characterized when parametric assumptions are imposed on the sampling distribution $G(\varphi)$, as shown in part (ii) of Proposition 3 for cases where the sampling distribution is Pareto. Note that the effect of $f_{X}$ is non-linear, since the stated parameter restrictions depends on $f_{X}-f_{D}$. If that difference is negative, a reduction in fixed market access costs always lowers unemployment.

In section 6 we calibrate the model towards U.S. data. This allows to assess whether the conditions required for a beneficial impact of trade liberalization on labor market outcomes are likely to be met in reality or not. The calibration will also highlight the differences across bargaining regimes. ${ }^{27}$

\subsection{Equilibrium with external economies of scale}

Labor market tightness, real wages and input diversity are determined jointly when there are external economies of scale $(\nu>0)$. Their equilibrium values follow from the Job Creation, Wage Curve and Labor Market Clearing conditions, as defined in Sections 3 and 5.1. To clarify

\footnotetext{
${ }^{27}$ It is easy to show that - everything else equal - unemployment reacts more strongly to aggregate productivity in the case of individual bargaining than in the case of collective bargaining when $b=0$. When $b>0$, the comparison is ambiguous. Since the ceteris paribus assumption across the two scenarios is problematic ( $\beta$ measures different effective bargaining power in each case), we compare scenarios in the quantitative exercise of section 6 .
} 
the analysis, we combine the Job Creation and Wage Curve into one equation that we label Equilibrium Tightness Condition (ETC). As the LMC, the ETC defines a mapping between input diversity $M$ and labor market tightness $\theta$. We can then combine the LMC and the ETC for each bargaining environment to pin down the equilibrium values of $M$ and $\theta$. Using (9) and (10) for individual, (12) and (11) for collective bargaining, we obtain

$$
\begin{aligned}
& E T C_{I}: M_{I}\left(\theta_{I}\right)=\left[\frac{\frac{c}{(1-\beta)(1-\delta)}\left(\frac{r+s}{m\left(\theta_{I}\right)}+\beta \theta_{I}\right)}{\tilde{\varphi}\left(\frac{\sigma-1}{\sigma-\beta}-b\right)}\right]^{\frac{\sigma-1}{\nu}} \\
& \operatorname{ETC}_{C}: M_{C}\left(\theta_{C}\right)=\left[\frac{\left(\frac{r+s}{1-\delta}\right) \frac{c}{m\left(\theta_{C}\right)}}{\tilde{\varphi}\left(\frac{\sigma-1}{\sigma}-b-\frac{\beta}{\sigma} \frac{\theta_{C} m\left(\theta_{C}\right)}{r+s}\right)}\right]^{\frac{\sigma-1}{\nu}} .
\end{aligned}
$$

The ETCs are upward-sloping in each bargaining regime because more input diversity raises efficiency and thus compensates the increase in recruitment costs as $\theta$ goes up. Given that the LMCs conditions are also increasing, equilibrium existence and uniqueness are not anymore ensured but can be established imposing empirically reasonable restrictions. ${ }^{28}$

Lemma 3 When $\nu \geq 0$, equilibrium tightness and input diversity are pinned down by the system $\{(22),(24)\}$ for the case of individual bargaining and by $\{(23),(25)\}$ for the case of collective bargaining. Assume that the aggregate matching function is Cobb-Douglas, so that $m(\theta)=$ $m_{0} \theta^{-\alpha}$, with $m_{0}>0$ and $\alpha \in(0,1)$. In case of individual bargaining, a sufficient condition for equilibrium existence and uniqueness is $\nu /(\sigma-1)<\alpha$. For the collective bargaining scenario, a sufficient condition is $\nu /(\sigma-1)<\min \left[\alpha, \frac{1}{2}\right]$.

Figure 3 shows the equilibrium conditions for the case of individual bargaining when wages are bargained at the individual level. Under the parameter restrictions presented in Lemma 3, both the ETC and the LMC start in the origin. The ETC is strictly convex while the LMC is strictly concave over the relevant parameter ranges. The LMC converges to some upper bound on input diversity $\bar{M}$ while the ETC diverges. The collective bargaining case looks almost identical. ${ }^{29}$ Hence, the existence of a unique equilibrium (point $E$ ) is guaranteed. As $\nu \rightarrow 0$,

\footnotetext{
${ }^{28}$ As explained in subsection 5.1, when $\sigma<\nu+1$, the LMCs conditions are decreasing in $\theta$. Hence, there always exists a unique equilibrium when this parameter restriction is satisfied. Yet, we do not focus on this case because it is neither theoretically realistic nor empirically relevant.

${ }^{29}$ The only difference is that the $E T C_{C}$ locus asymptotes towards some tightness $\bar{\theta}>0$ implicitly determined by $\frac{\beta}{\sigma} \frac{\bar{\theta} m(\bar{\theta})}{r+s}=\frac{\sigma-1}{\sigma}-b>0$.
} 


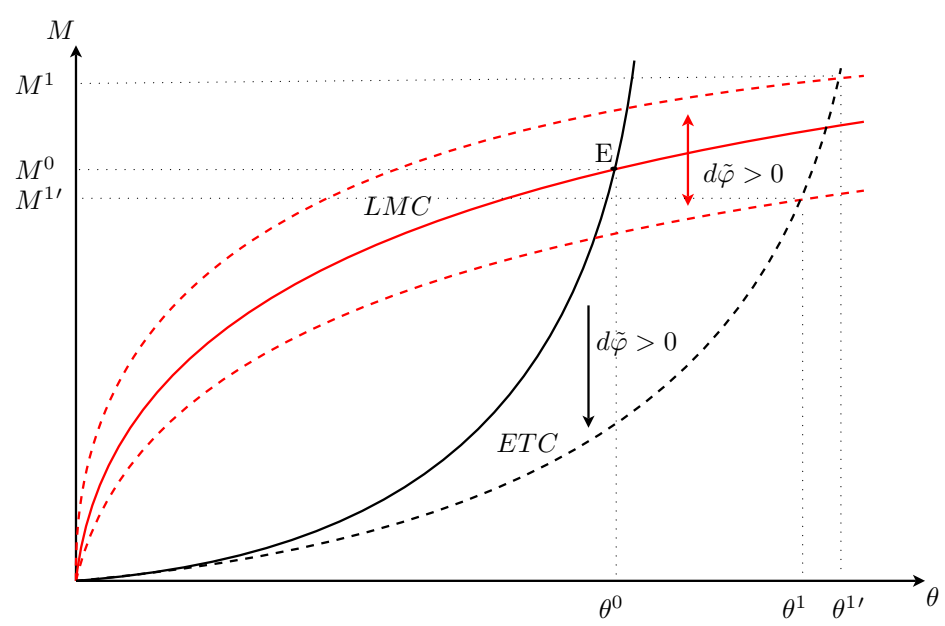

Figure 3: Determination of input diversity and labor market tightness in general equilibrium with $\nu>0$.

the ETC locus converges towards a vertical line, whose position is pinned down by average productivity $\tilde{\varphi}$ and labor market variables. ${ }^{30}$

The parameter restriction stated in Lemma 3 requires that the strength of the external scale effect is sufficiently low when compared to the elasticity of the matching function $\alpha$. Empirically, sectoral estimates of $\nu$ and $\alpha$ cluster around $0.5,{ }^{31}$ hence $\sigma$ would need to be above 2 . This requirement does not seem implausible empirically.

Only if $\nu>0$ do changes in labor market parameters affect aggregate productivity $\Phi$. Average productivity of input producer, however, remains unchanged, as Lemma 1 still applies. Hence, labor market institutions matter for aggregate productivity only through their effect on input diversity. Inspection of the equilibrium conditions reveals that higher levels of $b$ or $c$ rotate the ETC loci upwards, while they do not affect the LMC curves. In both bargaining regimes, those changes lower labor market tightness, real wages, and increase unemployment. In contrast, an

\footnotetext{
${ }^{30}$ When the flow-value of non market activity is not indexed to aggregate productivity but instead equal to an exogenous constant, the ETC locus has a positive intercept on the vertical axis. As can easily be seen from Figure 3, this implies that the model admits at least two equilibria or none. This explains why we have assumed from the outset that non market activity yields revenues proportional to $\Phi$. Janiak (2006) considers instead that they are purely exogenous and so, in order to circumvent the multiplicity issue, focuses on cases where $\sigma<\nu+1$. This is why he finds a negative relationship between variable trade cost reduction and employment.

${ }^{31}$ See Ardelean (2007) for estimates of the external scale effect and Pissarides and Petrongolo (2001) for estimates of the matching function parameters.
} 
improvement in the matching efficiency $m_{0}$ affects the ETC and the LMC curves. The LMC loci rotate upwards, while the ETC curves move in opposite direction: equilibrium tightness unambiguously increases, leading to higher real wages and lower unemployment.

To sum up, labor market parameters have a qualitatively similar impact on unemployment than in the standard Pissarides (2000) model with homogeneous firms and perfect competition on product markets. Notice also that economies of scale generate a negative relationship between the size of the economy, $L$, and the rate of unemployment. Given that such a correlation is not substantiated by the data, the model suggests that the marginal scale effect has to be small, either because of a low value of $\nu$ or a very high degree of input diversity.

\subsection{Trade liberalization and unemployment with external economies of scale}

We are now able to characterize the effect of trade liberalization on labor market outcomes when the production function exhibits economies of scale. This is done in the next proposition, which - as Proposition 3 - falls in two parts. Part (i) provides a sufficient condition for some trade liberalization scenarios to improve labor market outcomes. ${ }^{32}$ It does not impose any specific assumption on the productivity distribution. Conversely, part (ii) assumes that the productivity distribution is Pareto and provides necessary and sufficient conditions for trade to reduce the unemployment rate.

Proposition 4 Assume that there are economies of scale $(\nu>0)$ and that the existence and uniqueness condition in Lemma 3 is satisfied $(\nu /(\sigma-1)<\alpha)$.

(i) If $f_{X} \geq f_{D}$ a reduction of variable trade costs $\tau$ or an increase in the number of trading partners $n$ lead to a fall in the equilibrium rate of unemployment and a rise in the real wage, regardless of whether wages are bargained individually or collectively. A fall in fixed foreign distribution costs has an ambiguous effect on labor market outcomes.

(ii) Let firms draw their productivities from a Pareto distribution. Then, regardless of the wage bargaining regime, the equilibrium rate of unemployment falls and the real wage rises

(a) due to a reduction in $\tau$ or an increase in $n$ if and only if $\frac{\sigma-1}{(1-\nu) \gamma}\left(1+n \tau^{-\gamma}\left(f_{D} / f_{X}\right)^{\frac{\gamma}{\sigma-1}}\right) \geq$ $\frac{f_{D}}{f_{X}}-1$,

(b) due to a reduction in $f_{X}$ if and only if $\frac{\gamma^{2}(1-\nu)}{(\sigma-1)((\sigma-1)-\nu \gamma)} \geq \frac{f_{X}}{f_{X}-f_{D}}\left[1+n \tau^{-\gamma}\left(\frac{f_{D}}{f_{X}}\right)^{\frac{\gamma}{\sigma-1}}\right]$.

\footnotetext{
${ }^{32}$ Baldwin and Forslid (2006) provide conditions for different globalization scenarios to improve average productivity in a Melitz model with $\nu=1$ and $\varphi$ following the Pareto distribution.
} 
Proposition 4 generalizes Proposition 3 to cases with external economies of scale, as long as the additional parameter restriction ensuring existence and uniqueness of the equilibrium is satisfied. As discussed before and illustrated by our numerical exercise below, the requirements in Proposition 4 are largely satisfied by empirically reasonable parameter values. Accordingly, our theoretical analysis leads us to the conclusion that trade openness is likely to have a beneficial impact on labor market outcomes.

Part (ii) of Proposition 4 derives sufficient and necessary conditions under the Pareto assumption. Inspection of condition (a) shows that the higher economies of scale are, the more likely it is that labor market outcomes are improved by a reduction in export tariffs or an increase in the number of trading partners. Accordingly, when economies of scale are maximal $(\nu=1)$, as in Melitz (2003), condition (a) is always satisfied. The influence of $\nu$ is rather intuitive: trade raises not only productivity at the factory gate but also input diversity and this second effect is obviously more beneficial when economies of scales are strong.

Figure 3 illustrates our findings: when $\varphi$ goes up, the ETC locus rotates downwards; the effect on the LMC curve, however, depends on parameters. Nevertheless, even when the LMC locus rotates down, the net effect on $\theta$ is positive in both wage bargaining scenarios. The effect on input diversity, in contrast, remains ambiguous.

\section{$6 \quad$ Numerical Illustration}

Although our theoretical model can be fully characterized analytically, the effect of trade liberalization on labor market outcomes is potentially ambiguous, a beneficial effect requiring specific restrictions on exogenous parameters. We therefore calibrate the model in order to assess whether those restrictions are likely to hold in reality. We simulate the labor market effects of different trade liberalization scenarios to shed light on the quantitative importance of the trade-unemployment nexus. The simulation also shows how the impact of liberalization depends on the nature of the bargaining regime and on the strength of external economies of scale. Clearly, our numerical exercise is merely illustrative since we model a world of perfectly symmetric countries. Also note that we focus on the long-run and neglect adjustment dynamics in the two state variables of the model, $\theta$ and $\tilde{\varphi}$.

Our calibration follows standard practice, as versions of the Melitz (2003) and of the Pissarides search-matching model have been frequently calibrated in the literature. Regarding the 
product market, we follow Bernard, Redding, and Schott (2007); calibration of the labor market side is close to Shimer (2005). ${ }^{33}$

\subsection{Calibration}

In the following, we describe the calibration of our model. Table 1 summarizes all parameter values and statistics are for monthly values.

Sampling distribution and aggregate production function. As Bernard et al. (2007), Ghironi and Melitz (2005) or Helpman, Melitz, Yeaple (2004), we assume that firm productivities are distributed according to a Pareto distribution. Setting the scale parameter of that distribution to unity, the probability density is $g(\varphi)=\gamma \varphi^{-(1+\gamma)}$. The shape parameter $\gamma$ governs the rate of decay of the distribution. We need to impose $\gamma>\sigma-1$ to ensure that the variance of the sales distribution is finite. As Bernard, Redding, and Schott (2007), we set $\gamma=3.4$ and choose $\sigma=3.8$. Ardelean (2007) estimates the 'love for variety' parameter $\nu$ for different U.S. industries. Taking the average, we set $\nu=0.41$ in our baseline calibration. ${ }^{34}$

Variable and fixed costs of trade and entry. We set the number of potential workers equal to $L=142$ Mio. which matches the American labor force in 2000. We choose variable trade $\operatorname{costs} \tau$ equal to 1.3 as Ghironi and Melitz (2005). Given the Pareto distribution, the share of firms that export is given by

$$
\varrho=\tau^{-\gamma}\left(\frac{f_{D}}{f_{X}}\right)^{\frac{\gamma}{1-\sigma}}
$$

That number is put at about $21 \%$ by Bernard et al. (2003). Together with $\tau=1.3$, this pins down the ratio $f_{X} / f_{D}$ at about 1.7 . Setting the number of trading partners $n=2$, we obtain an overall degree of openness (export sales over total sales) of about 19\%. Finally, we calibrate $F_{E}=4125$ and $f_{D}=22.5$ such that the equilibrium labor market tightness produced by our model is 0.5 (Hall, 2005) and the average firm size is equal to 19 (Axtell, 2001). ${ }^{35}$

\footnotetext{
${ }^{33}$ See Felbermayr and Prat (2007) for a related calibration exercise for the case of a closed economy.

${ }^{34}$ See Table 1 in Ardelean (2007). We have chosen to use the simple mean value of $\nu$ for the U.S. in our benchmark calibration. We do not use Ardelean's estimate of $\sigma$ since she identifies this parameter under the assumption of homogeneous firms.

${ }^{35}$ The relation between $F_{E}$ and $f_{D}$ is of the same order of magnitude than in Ghironi and Melitz (2005).
} 
Separation shocks. Job separations occur either because a firm exit the market or because the match itself is destroyed. Bartelsmann et al. (2004) estimates are centered around a monthly hazard rate of exiting the market $\delta=0.96 \%$. Match-specific shocks account for the job separations that are left unexplained by firm-specific shocks. Shimer (2005) estimates the monthly job separation rate to be on average equal to $s=0.034$. It follows that the monthly Poisson arrival rate of match-specific shocks $\chi=\frac{s-\delta}{1-\delta} \approx 0.024$.

Parameters for the matching function and cost of vacancy-posting. We postulate a Cobb-Douglas matching function $m(\theta)=m_{0} \theta^{-\alpha}$, whose elasticity $\alpha$ is set equal to 0.5 following Petrongolo and Pissarides (2001). The assumption of constant returns to matching implies that $\theta$ is equal to the job finding rate $m(\theta) \theta$ over the job filling rate $m(\theta)$. Shimer (2005) estimates the monthly job finding rate in the U.S. to be around 0.45, whereas Hall (2005) finds an average labor market tightness $\theta$ of around 0.5 . It follows that the monthly job filling rate $m(\theta)$ is equal to $0.45 / 0.5 \approx 0.9$, so that $m_{0} \approx 0.64$. We target the flow income of unemployment to be $40 \%$ of the equilibrium real wage, which yields a value for $b$ of around $0.3{ }^{36}$ Firms' vacancy posting costs are fixed to 1.1 times the monthly wage (Ebell and Haefke, 2006). We calibrate those costs at 40.98 , which appears large compared to flow fixed costs. Note, however, that the equivalent monthly flow cost is just 1.69 .

Bargaining power and value of non-market activity. The results of Abowd and Allain (1996) suggest that, in the case of individual bargaining, workers' bargaining power is close to $\beta_{I}=0.5$. However, when wages are collectively bargained, $\beta$ plays a different role as the effective bargaining power of workers (taking into account the outside option) is much larger. Cahuc et al. (2002) have estimated trade unions' bargaining power at French firms and suggest $\beta_{C}=0.2$. Our choice of $\beta$ for the different bargaining regimes yields equilibrium unemployment rates that are reasonable enough: $7 \%$ for the case of individual bargaining and $11 \%$ for collective bargaining. Notice that wages are approximately equal in both benchmark scenarios which allow us to leave the other parameters unchanged without loss of generality.

\footnotetext{
${ }^{36}$ Recall that we have made the value of unemployment proportional to aggregate productivity.
} 
Table 1: Calibration-Parameter Values

\begin{tabular}{|c|c|c|c|}
\hline Parameter & Interpretation & Value & Source \\
\hline & External parameter estimates & & \\
\hline$L$ & Labor endowment per country & 142 Mio. & American labor force \\
\hline$\beta_{I}$ & Bargaining power, individual bargaining & 0.5 & Abowd and Allain (1996) \\
\hline$\beta_{C}$ & Bargaining power, collective bargaining & 0.2 & Cahuc et al. (2002)] \\
\hline$\alpha$ & Elasticity of matching function & 0.5 & Petrongolo and Pissarides (2001) \\
\hline$s$ & Monthly job destruction & $3.4 \%$ & Shimer (2005) \\
\hline$r$ & Monthly discount rate & $0.33 \%$ & $4 \%$ annual interest rate \\
\hline$\delta$ & Monthly rate of firm exit & $0.97 \%$ & Bartelsmann et al. (2004) \\
\hline$\sigma$ & Elasticity of substitution & 3.8 & Bernard et al. (2007) \\
\hline$\gamma$ & Decay of productivity distribution & 3.4 & Bernard et al. (2007) \\
\hline$\nu$ & Degree of external economies of scale & 0.41 & Ardelean (2007) \\
\hline \multirow[t]{2}{*}{$\tau$} & Iceberg trade costs & 1.3 & Ghironi \& Melitz (2005) \\
\hline & Parameters matched to moments in the $d$ & & \\
\hline$b$ & Value of non-market activity & 0.32 & $40 \%$ effective replacement rate \\
\hline$m_{0}$ & Scale of matching function & 0.64 & Monthly job finding rate $=0.45$ \\
\hline$c$ & Cost of posting a vacancy & 40.98 & $\begin{array}{l}1.1 \text { times monthly wage } \\
\text { (Ebell and Haefke, 2006) }\end{array}$ \\
\hline$f_{E}$ & Entry costs & 4125 & $\theta \approx 0.5$ (Hall, 2005) \\
\hline$f_{D}$ & Domestic flow fixed costs & 22.5 & $\begin{array}{l}\text { Average firm size }=19 \\
(\text { Axtell, 2001) }\end{array}$ \\
\hline \multirow[t]{2}{*}{$f_{X}$} & Fixed foreign market access costs & 38.25 & $\varrho=0.21$ (Bernard et al., 2003) \\
\hline & $\underline{\text { Normalized Parameters }}$ & & \\
\hline $\mathrm{P}$ & Aggregate price level & 1 & \\
\hline$n+1$ & Number of countries & 3 & \\
\hline
\end{tabular}




\subsection{The labor market effects of trade liberalization}

The calibrated parameters summarized in Table 1 show that the necessary condition, $f_{X} / f_{D}>1$, for lower variable trade costs to reduce unemployment is very likely to be met. Foreign relative to domestic distribution costs need to be large for the model to be consistent with observed low export participation rates of firms. Moreover, the sufficient and necessary condition for foreign market access costs is met in the neighborhood of the calibrated value of $f_{X} .{ }^{37}$ Hence, from Table 1 it is possible to conclude that all three trade liberalization scenarios lead to lower equilibrium unemployment and higher real wages, regardless of the bargaining environment.

By simulating the model, we can go beyond these findings. First, while the theoretical analysis is local, our numerical exercise allows for a global analysis; this is particularly relevant for fixed costs of accessing foreign markets as they have highly non-linear effect. Second, by means of simulation we can quantify the unemployment-reducing effect of trade liberalization and compare it across our two bargaining scenarios. Finally, the simulation makes it possible to check the importance of the external economies of scale parameter $\nu$.

Figure 4 illustrates the effect of trade liberalization on labor market outcomes. The first row of the panel studies variations in variable trade costs $(\tau)$, the second in the number of countries to which any country may export $(n)$, and the third row shows the effects of changing fixed costs of foreign market access. For each scenario, we report the case of individual bargaining in the left graph, and of collective bargaining in the right graph. All pictures have the real wage $W$ on the right ordinate and the unemployment rate $U$ (in percent) on the left ordinate. Obviously, the intersection of the $W$ and the $U$ curves has no particular meaning. The baseline calibration at $\tau=1.3, n=2, f_{X}=38.25$ shows an unemployment rate of $7 \%$ and a wage rate of 37.1 in the case of individual bargaining. For collective bargaining, labor market distortions are stronger, so that the unemployment rate is higher (10.9\%) and the real wage slightly lower (36.9).

The first row of Figure 4 illustrates that lower variable trade costs $\tau$ can have a sizable effect on labor market outcomes. In the case of individual bargaining, moving $\tau$ from 1.6 to 1 lowers the unemployment rate by 1 percentage point from $7.4 \%$ to $6.4 \%$ and increases the wage rate by $35.3 \%$ from 33.4 to 45.2 . In the case of collective bargaining, unemployment falls by 0.1 percentage points from $11 \%$ to $10.9 \%$ while the wage rate goes up by $35.2 \%$ from 33.2 to 44.9 . Hence, while the nature of the bargaining regime does not matter for the qualitative implications

\footnotetext{
${ }^{37}$ Moreover, the values of $\nu, \sigma$, and $\alpha$ provided by the empirical literature suggest that the existence and uniqueness requirement of Lemma 3 is fairly weak.
} 
Individual bargaining
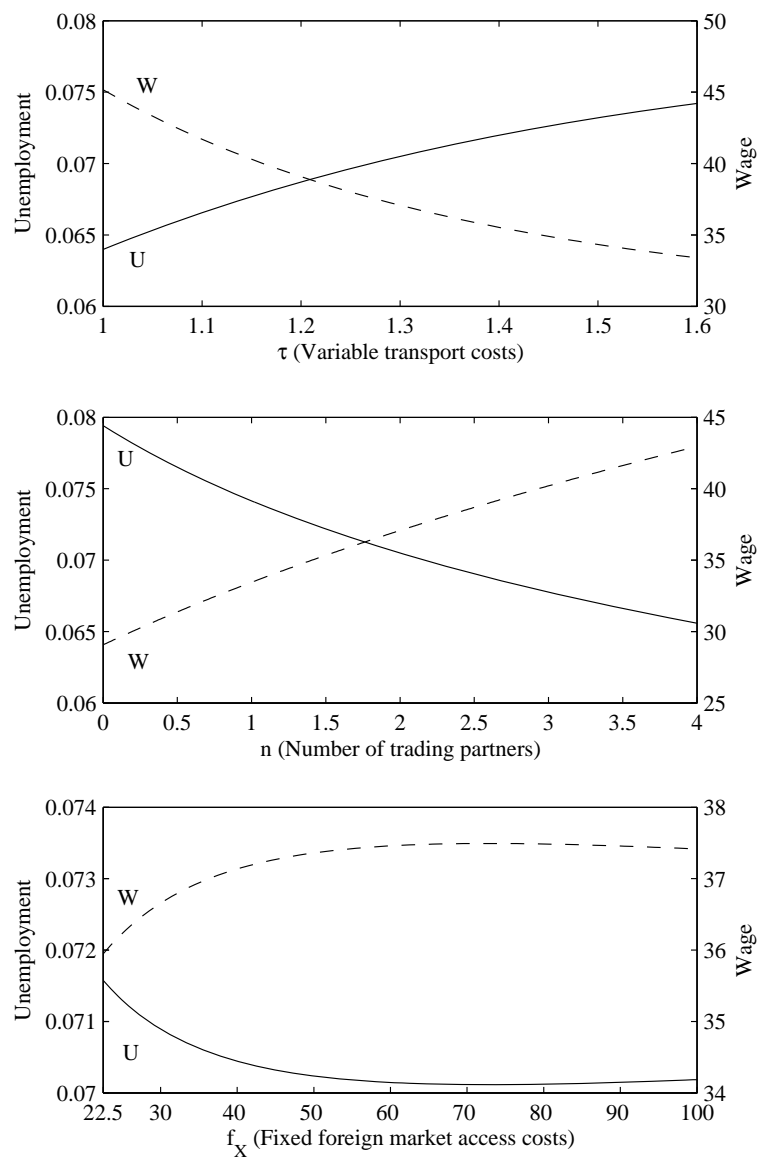

Collective bargaining
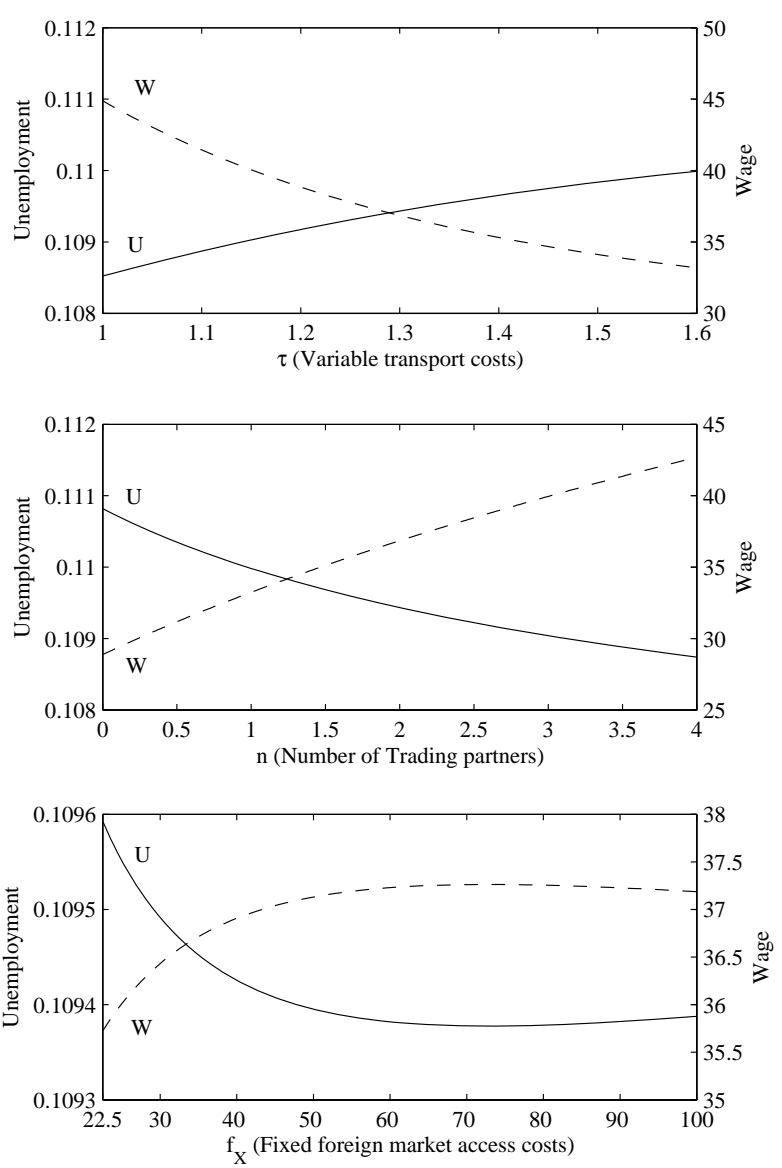

Figure 4: Simulation results: labor market effects of different trade liberalization scenarios. 
of trade reform, the quantitative effects are drastically different. With individual bargaining, the reduction of the unemployment rate is much more pronounced, despite its lower initial level. Interestingly, the real wage goes up almost as strongly as with collective bargaining. ${ }^{38}$

Figure 5 in the Appendix illustrates the product market effects of trade liberalization in analogy to Figure 4. Strikingly, trade liberalization reduces input diversity while it boosts the productivity of the average firm. This is the anti-variety effect described in Baldwin and Forslid (2006). Given that we set external economies of scale at a lower level than in the literature $(\nu=0.41$ versus 1.00), trade liberalization has a stronger effect on aggregate productivity $\Phi$ and, hence, unemployment.

The second row in Figure 4 relates to variation in the number of export markets. In the baseline case we have $n=2$. Now, consider an increase of $n$ to, say, 4 . In the case of individual bargaining, the wage rate goes up to about 42 while the unemployment rate falls to $6.6 \%$. As with variation in $\tau$, any change in $n$ has stronger unemployment effects with individual as compared to collective bargaining.

Finally, consider the case of a change in the fixed foreign market access cost $f_{X}$. A marginal reduction in $f_{X}$ at the baseline equilibrium $\left(f_{X}=38.25\right)$ leads to a reduction in the unemployment rate and to an increase in the real wage. Lowering $f_{X}$ below about 70 reverts the result: now, trade liberalization turns out to deteriorate labor market outcomes. The logic for this result becomes transparent in Figure 4 in the Appendix. When $f_{X}$ falls, input diversity goes up, but average productivity $(\tilde{\varphi})$ falls if $f_{X}$ dips below some threshold. The latter effect is due to a weaker selection effect: lower $f_{X}$ reduces the prices charged by incumbent exporters, but also allows less efficient firms to export. The net effect is ambiguous ex ante, and becomes negative if $f_{X}$ is low enough. The case of collective bargaining is similar, with the variation in the unemployment rate generally smaller than with individual bargaining. Note that doubling $f_{X}$ from its baseline value increases unemployment only by 0.06 percentage points. The increase in $\tau$ required to generate the same unemployment effect is just 0.03 (from 1.3 to 1.33). Hence, lower variable trade costs appear to have a much stronger impact on labor market outcomes than lower fixed market access costs.

Table 2 explores the importance of the external scale parameter $\nu$. Holding everything else

\footnotetext{
${ }^{38}$ The discussed reduction of $\tau$ from 1.6 to 1 describes the entirely unrealistic transition from costly trade to a situation where no trade-costs whatsoever exist. Since higher $\tau$ lowers the effective labor productivity, reducing $\tau$ by $60 \%$ has a massive effect on aggregate productivity. With $n$ growing towards infinity, the share of imported inputs converges towards 1 and a reduction in $\tau$ is equivalent to an increase in the marginal productivity of labor.
} 


\section{Individual bargaining}

\begin{tabular}{l|c|rrr|r|rrr} 
& & $\tau=1.0$ & $\tau=1.1$ & $\tau=1.2$ & $\tau=1.3$ & $\tau=1.4$ & $\tau=1.5$ & $\tau=1.6$ \\
\hline$\nu=0.49$ & $u$ & 4.6 & 4.8 & 4.9 & 5.1 & 5.2 & 5.3 & 5.3 \\
& $w$ & 88.5 & 81.6 & 76.5 & 72.5 & 69.5 & 67.1 & 65.3 \\
$\nu=0.45$ & $u$ & 5.4 & 5.7 & 5.8 & 6.0 & 6.1 & 6.2 & 6.3 \\
& $w$ & 62.9 & 58.1 & 54.4 & 51.6 & 49.4 & 47.8 & 46.5 \\
$\nu=0.41$ & $u$ & 6.4 & 6.7 & 6.9 & 7.0 & 7.2 & 7.3 & 7.4 \\
& $w$ & 45.2 & 41.7 & 39.1 & 37.1 & 35.6 & 34.4 & 33.4 \\
$\nu=0.37$ & $u$ & 7.5 & 7.8 & 8.0 & 8.2 & 8.4 & 8.6 & 8.7 \\
& $w$ & 32.8 & 30.3 & 28.4 & 26.9 & 25.8 & 25.0 & 24.3 \\
$\nu=0.33$ & $u$ & 8.7 & 9.1 & 9.3 & 9.6 & 9.8 & 9.9 & 10.1 \\
& $w$ & 24.0 & 22.2 & 20.8 & 19.8 & 18.9 & 18.3 & 17.8 \\
\hline
\end{tabular}

\section{Collective bargaining}

\begin{tabular}{l|c|rrr|r|rrr} 
& & $\tau=1.0$ & $\tau=1.1$ & $\tau=1.2$ & $\tau=1.3$ & $\tau=1.4$ & $\tau=1.5$ & $\tau=1.6$ \\
\hline$\nu=0.49$ & $u$ & 10.6 & 10.7 & 10.7 & 10.7 & 10.7 & 10.7 & 10.7 \\
& $w$ & 88.6 & 81.8 & 76.7 & 72.7 & 69.7 & 67.4 & 65.5 \\
$\nu=0.45$ & $u$ & 10.7 & 10.8 & 10.8 & 10.8 & 10.8 & 10.8 & 10.8 \\
& $w$ & 62.8 & 58.0 & 54.3 & 51.5 & 49.4 & 47.7 & 46.4 \\
$\nu=0.41$ & $u$ & 10.9 & 10.9 & 10.9 & 10.9 & 11.0 & 11.0 & 11.0 \\
& $w$ & 44.9 & 41.5 & 38.9 & 36.9 & 35.3 & 34.1 & 33.2 \\
$\nu=0.37$ & $u$ & 11.0 & 11.1 & 11.1 & 11.1 & 11.2 & 11.2 & 11.2 \\
& $\mathrm{w}$ & 32.4 & 29.9 & 28.0 & 26.6 & 25.5 & 24.6 & 24.0 \\
$\nu=0.33$ & $\mathrm{u}$ & 11.2 & 11.3 & 11.3 & 11.4 & 11.4 & 11.5 & 11.5 \\
& $\mathrm{w}$ & 23.6 & 21.8 & 20.4 & 19.3 & 18.5 & 17.9 & 17.4 \\
\hline
\end{tabular}

The combination $\tau=1.3, \nu=0.41$ represents our benchmark specification. $u$ is the unemployment rate, $w$ is the real wage.

Table 2: Labor market effects of lower variable trade costs $(\tau)$ with various degrees of external economies of scale $(\nu)$. 
equal, a higher value of $\nu$ (stronger scale effect) leads to lower unemployment, regardless of the bargaining regime. Also, the extent to which trade liberalization reduces the equilibrium rate of unemployment depends on the value of $\nu$. The quantitative importance of increased input diversity is massive: as $\nu$ moves up from its individual bargaining benchmark level $\nu=0.41$ to 0.49 , the rate of unemployment decreases by about 2 percentage points; when $\nu$ falls by the same amount, unemployment goes up even more strongly. Similarly, the real wage reacts strongly, too. In the case of collective bargaining, the effect of $\nu$ on the unemployment rate is comparatively small: This is due to the fact that variation in $\nu$ mainly affects the wage rate. Table 3 in the Appendix reports the effects of lower $f_{X}$ on labor market outcomes with different $\nu$. Compared with the baseline case, higher $\nu$ increases the sensitivity of both the unemployment rate and the wage as $f_{X}$ changes.

Corsetti et al. (2007) discuss the importance of 'love for variety' in an open-macro model with homogeneous firms. They find that the welfare properties of their model crucially depends on $\nu$. Our results confirm this finding in the context of search unemployment, heterogeneous firms, and trade.

\section{Conclusion}

Bringing together two important established but hitherto unrelated models in the trade and labor literatures - the Melitz (2003) model of trade with heterogeneous firms, and the Pissarides (2000) search and matching approach to unemployment - this paper develops conditions under which the selection effect of trade improves labor market outcomes. While there is strong empirical support in favor of turnover on labor markets and in line with the selection effect of trade, there is much less consensus on how to model wage bargaining; hence, the present paper discusses two environments, individual bargaining and collective firm-level bargaining.

The proposed framework is surprisingly tractable, in spite of the existence of heterogeneous firms, various types of trade costs, monopoly power on product markets, and monopsony power due to search frictions on the labor market. The equilibrium is recursive since labor market conditions do not affect average productivity (the converse, of course, is not true). If the model exhibits economies of scale, there is a wedge between average and aggregate productivity. Then, aggregate productivity does depend on labor market outcomes.

The paper shows that the labor market implications of trade liberalization are determined 
by the effect of trade on aggregate productivity. This latter relation, however, depends on parameter constellations. To sort out the ambiguities, we calibrate the model towards U.S. data. We find that different trade liberalization scenarios all improve labor market outcomes, regardless of the bargaining environment. Moreover, the reduction in the unemployment rate is numerically non-trivial, in particular when wages are bargained individually and economies of scale are important.

Compared to existing models that combine search unemployment and heterogeneous firms, our treatment features forward-looking firms, micro-founds the wage determination, and allows one to derive the main results without any assumptions on the distribution of firm productivities. External economies of scale are shown to be important for the model's properties. Existence and uniqueness do not require strong assumptions on parameters, and the model is straightforwardly calibrated. There are, however, two obvious and interesting extensions which we have to relegate to future research.

First, our approach focuses on long-run equilibria. This precludes the analysis of potentially interesting short-run adjustments, which result from the fact that the mass of producers adjusts only sluggishly to a changed environment due to sunk entry costs. Most empirical studies on the interaction between trade liberalization and labor turnover capture short to medium-run correlations, so that our model has little to say relative to their results. Moreover, any sensible welfare analysis requires to weigh potential losses along the transition path against the positive long-run effects.

Second, our conclusions are limited to the impact of multilateral trade liberalization amongst symmetric countries. Hence, we cannot say much about the recent surge in bilateral trade treaties or, even more importantly, about the effect on employment of trade liberalization with emerging countries such as China or India. We therefore believe that the most promising direction for further research would be to extend the model to cases where countries differ with respect to sizes, productivity levels and institutions. This will probably be a rather demanding project since addressing country asymmetries has proved difficult in the literature, in particular if one is not willing to narrow the analysis to two countries or to allow for a numéraire sector whose output is costlessly tradable. 


\section{References}

[1] Abowd, John M., and Laurence Allain (1996), Compensation Structure and Product Market Competition, Annales d'Economie et de Statistique 41/42: 207-18.

[2] Acemoglu, Daron, and William Hawkins (2006), Equilibrium Unemployment in a Generalized Search Model, mimeo, MIT.

[3] Ardelean, Adina (2007), How Strong is Love Of Variety? mimeo, Purdue University.

[4] Axtell, Robert L. (2001), Zipf distribution of U.S. firm sizes, Science 293(5536): 18181820.

[5] Baldwin, Richard E., and Rikard Forslid (2006), Trade Liberalization with Heterogenous Firms, NBER Working Papers 12192.

[6] Bartelsman, Eric, John Haltiwanger, and Stefano Scarpetta (2004), Microeconomic Evidence of Creative Destruction in Industrial and Developing Countries, IZA Discussion Paper No. 1374.

[7] Bartelsman, Eric, John Haltiwanger, and Stefano Scarpetta (2005), Comparative Analysis of Firm Demographics and Survival: Evidence From Micro-level Sources in OECD Countries. Industrial and Corporate Change 14: 365-391.

[8] Barth, Erling, and Josef Zweimüller (1995), Relative Wages under Decentralized and Corporatist Bargaining Systems, Scandinavian Journal of Economics 97(3): 369-84.

[9] Benassy, Jean-Pascal (1996), Taste for variety and optimum production patterns in monopolistic competition, Economics Letters 52(1): 41-47.

[10] Bernard, Andrew B., Jonathan Eaton, J. Bradford Jensen, and Samuel Kortum (2003), Plants and Productivity in International Trade, American Economic Review 93: 1268-1290.

[11] Bernard, Andrew B., Stephen J. Redding, and Peter K. Schott (2007), Comparative Advantage and Heterogeneous Firms, Review of Economic Studies 74(1): 31-66.

[12] Bertola, Giuseppe, and Ricardo J. Caballero (1994), Cross-Sectional Efficiency and Labour Hoarding in a Matching Model of Unemployment, Review of Economic Studies 61: 435-56.

[13] Bertola, Giuseppe, and Pietro Garibaldi, (2001), Wages and the Size of Firms in Dynamic Matching Models, Review of Economic Dynamics 4(2): 335-368. 
[14] Binmore, Kenneth, Ariel Rubinstein, and Ashler Wolinsky (1986), The Nash Bargaining Solution in Economic Modelling, Rand Journal of Economics 17(2): 176-188.

[15] Blanchard, Olivier, and Francesco Giavazzi (2003), Macroeconomic Effects of Regulation and Deregulation in Goods and Factor Markets, Quarterly Journal of Economics 118: 879-907.

[16] Cahuc, Pierre, Christian Gianella, Dominique Goux, and André Zylberberg (2002), Equalizing Wage Differences and Bargaining Power: Evidence From a Panel of French Firms, CEPR Discussion Paper 3510.

[17] Corsetti, Giancarlo, Philippe Martin, and Paolo Pesenti (2007), Productivity, terms of trade and the home market effect, Journal of International Economics 73(1), 99-127.

[18] Davidson, Carl, Lawrence Martin, and Steven Matusz (1988), The Structure of Simple General Equilibrium Models with Frictional Unemployment, Journal of Political Economy 96(6): 12671293.

[19] Davidson, Carl, Steven J. Matusz, and Andrei Shevchenko (2007), Globalization and Firm Level Adjustment with Imperfect Labor Markets, mimeo, Michigan State University.

[20] Davis, Donald R., and James Harrigan (2007), Good Jobs, Bad Jobs, and Trade Liberalization, NBER Working Paper 13139.

[21] Ebell, Monique, and Christian Haefke (2006), Product Market Deregulation and Labor Market Outcomes, IZA Discussion Paper No. 1946.

[22] Egger, Hartmut, and Udo Kreickemeier (2007), Firm Heterogeneity and the Labor Market Effects of Trade Liberalization, International Economic Review, forthcoming.

[23] Felbermayr, Gabriel, and Julien Prat (2007), Product Market Regulation, Firm Selection and Unemployment, IZA Working Paper 2754.

[24] Ghironi, Fabio, and Marc Melitz (2005), International Trade and Macroeconomic Dynamics with Heterogeneous Firms, Quarterly Journal of Economics 120: 865-915.

[25] Hall, Robert (2005), Employment Fluctuations with Equilibrium Wage Stickiness, American Economic Review, 95(1): 50-65.

[26] Helpman, Elhanan (2006), Trade, FDI, and the Organization of Firms, Journal of Economic Literature 44: 589-630. 
[27] Helpman, Elhanan, and Oleg Itskhoki (2007), Labor Market Rigidities, Trade and Unemployment, NBER Working Paper 13365.

[28] Helpman, Elhanan, Marc J. Melitz, and Stephen R. Yeaple (2004), Export versus FDI with Heterogeneous Firms, American Economic Review 94(1): 300-316.

[29] Hopenhayn, Hugo A. (1992), Entry, Exit, and Firm Dynamics in Long Run Equilibrium, Econometrica 60(5): 1127-50.

[30] Janiak, Alexandre (2006), Does Trade Liberalization Lead to Unemployment? Theory and Some Evidence, mimeo, Universite Libre de Bruxelles.

[31] Koeniger, Winfried, and Julien Prat (2006), Employment Protection, Product Market Regulation and Firm Selection, Economic Journal 117(521): F302-F332.

[32] Krugman, Paul (1980), Scale Economies, Product Differentiation, and the Pattern of Trade, American Economic Review 70(5): 950-59.

[33] Melitz, Marc (2003), The impact of trade on intraindustry reallocations and aggregate industry productivity, Econometrica 71: 1695-1725.

[34] Mitra, Devashish, and Priya Ranjan (2007), Offshoring and Unemployment, NBER Working Paper 13149.

[35] Pissarides, Christopher A. (2000), Equilibrium Unemployment Theory, 2nd edition, Cambridge, Mass: MIT Press.

[36] Pissarides, Christopher A., and Barbara Petrongolo (2001), Looking into the black box: A survey of the matching function, Journal of Economic Literature 39: 390-431.

[37] Scheve, Kenneth F., Slaughter, Matthew J. (2001), Globalization and the Perceptions of American Workers, Institute for International Economics, Washington, DC.

[38] Shimer, Robert (2005), The Cyclical Behavior of Equilibrium Unemployment and Vacancies, American Economic Review, 95(1): 25-49.

[39] Stole, Lars A., and Jeffrey Zwiebel (1996), Intra-firm Bargaining under Non-Binding Contracts, Review of Economic Studies 63: 375-410. 


\section{A Proofs}

Proof of Proposition 1. To solve the surplus-splitting rule (8), notice that the optimality condition (5) does not vary with the level of the control variable $v_{I}$. Hence, the optimal firm size remains constant through time, so that $l_{I}=l_{I}^{\prime}$. This condition and the envelope theorem enable us to rewrite (6) as

$$
\frac{\partial J_{I}\left(l_{I}, \varphi\right)}{\partial l_{I}}=\left(\frac{1}{r+s}\right)\left[\frac{\partial R\left(l_{I} ; \varphi\right)}{\partial l_{I}}-w_{I}\left(l_{I}, \varphi\right)-\frac{\partial w_{I}\left(l_{I}, \varphi\right)}{\partial l_{I}} l_{I}\right] .
$$

Reinserting this expression together with $E_{I}(\varphi)-U_{I}=\left(w_{I}\left(l_{I}, \varphi\right)-r U_{I}\right) /(r+s)$ into (8) yields

$$
\begin{aligned}
w_{I}\left(l_{I}, \varphi\right) & =\beta \frac{\partial R\left(l_{I} ; \varphi\right)}{\partial l_{I}}+(1-\beta) r U_{I}-\beta \frac{\partial w_{I}\left(l_{I}, \varphi\right)}{\partial l_{I}} l_{I} \\
& =\beta\left(\frac{\sigma-1}{\sigma}\right)\left[\frac{Y_{I}}{M_{I}^{(1-\nu)}}\left(1+I(\varphi) n \tau^{1-\sigma}\right)\right]^{1 / \sigma} \varphi^{\frac{\sigma-1}{\sigma}} l_{I}^{-\frac{1}{\sigma}}+(1-\beta) r U_{I}-\beta \frac{\partial w_{I}\left(l_{I}, \varphi\right)}{\partial l_{I}} l_{I} .
\end{aligned}
$$

Equation (26) is a linear differential equation in $l_{I}$. One can verify by direct substitution ${ }^{39}$ that

$$
w_{I}\left(l_{I}, \varphi\right)=(1-\beta) r U_{I}+\beta\left(\frac{\sigma}{\sigma-\beta}\right) \frac{\partial R\left(l_{I} ; \varphi\right)}{\partial l_{I}}
$$

solves (26). Equation (27) is the counterpart of the Wage curve in the standard search-matching model. The Job Creation curve is derived reinserting the demand function (2) into (27) and differentiating the resulting equation with respect to $l_{I}$

$$
\frac{\partial w_{I}\left(l_{I}, \varphi\right)}{\partial l_{I}} l_{I}=-\frac{1}{\sigma}\left[\beta\left(\frac{\sigma}{\sigma-\beta}\right) \frac{\partial R\left(l_{I} ; \varphi\right)}{\partial l_{I}}\right] .
$$

This expression allows us to substitute $\left(\partial w_{I}\left(l_{I}, \varphi\right) / \partial l_{I}\right) l_{I}$ in $(7)$ to obtain

$$
w_{I}\left(l_{I}, \varphi\right)=\left(\frac{\sigma}{\sigma-\beta}\right) \frac{\partial R\left(l_{I} ; \varphi\right)}{\partial l_{I}}-\left(\frac{r+s}{1-\delta}\right) \frac{c}{m\left(\theta_{I}\right)} .
$$

Finally, we express the Wage Curve as a function of $\theta_{I}$ by reinserting (27) into (28)

$$
w_{I}\left(l_{I}, \varphi\right)=r U_{I}+\left(\frac{\beta}{1-\beta}\right)\left(\frac{r+s}{1-\delta}\right) \frac{c}{m\left(\theta_{I}\right)} .
$$

It follows that wages are identical across firms. Thus the workers' outside option reads

$$
r U_{I}\left(\theta_{I}\right)=b \Phi_{I}+\theta_{I} m\left(\theta_{I}\right)\left(\frac{w_{I}-r U_{I}}{r+s}\right)=b \Phi_{I}+\frac{\beta}{1-\beta}\left(\frac{c \theta_{I}}{1-\delta}\right),
$$

\footnotetext{
${ }^{39}$ See Bertola and Garibaldi (2001) or Ebell and Haefke (2006) for a detailed solution of a similar ODE by the method of variation of parameters.
} 
where (29) is used to drop the dependence of $w_{I}$ on $l_{I}$ and $\varphi$. The Wage curve in Proposition 1 follows after reinserting the expression of $U_{I}$ into (29). To simplify the Job Creation curve, consider first a firm that does not export, so that $I(\varphi)=0$. In this case, it is easily seen that the iso-elastic demand (2) implies $\partial R\left(l_{I} ; \varphi\right) / \partial l_{I}=p_{D}\left(l_{I} ; \varphi\right) \varphi(\sigma-1) / \sigma$. This equality also holds true for exporting firms because they are facing the same domestic demand than non-exporting firms and that marginal revenues are equalized across markets. To see this formally, notice that

$$
\begin{aligned}
\frac{\partial R\left(l_{I} ; \varphi\right)}{\partial l_{I}} & =\left(\frac{\sigma-1}{\sigma}\right)\left[\frac{Y_{I}}{M_{I}^{(1-\nu)}}\left(1+n \tau^{1-\sigma}\right)\right]^{1 / \sigma} \varphi q\left(l_{I} ; \varphi\right)^{-\frac{1}{\sigma}} \\
& =\left(\frac{\sigma-1}{\sigma}\right)\left(\frac{Y_{I}}{M_{I}^{(1-\nu)}}\right)^{1 / \sigma} q_{D}\left(l_{I} ; \varphi\right)^{-\frac{1}{\sigma}} \varphi=\left(\frac{\sigma-1}{\sigma}\right) p_{D}\left(l_{I} ; \varphi\right) \varphi \text {, when } I(\varphi)=1 .
\end{aligned}
$$

The second equality holds true because output is optimally allocated across markets when $q_{X}=q_{D} \tau^{1-\sigma}$. Equation (28) therefore implies that $p_{D}(\varphi) \varphi=p_{D}(\tilde{\varphi}) \tilde{\varphi}=\Phi$, where the last equality follows from the definition of $\tilde{\varphi}$. These simplifications lead to the Job Creation condition reported in Proposition 1.

The uniqueness of the equilibrium is ensured since the Wage curve is increasing in $\theta$ and the Job Creation curve decreasing. For the same reason, a necessary and sufficient condition for existence is that the intercept of the Wage curve be smaller than that of the Job Creation curve, which yields the condition stated in Proposition 1.

Proof of Corollary 1. Combining the Job Creation and Wage curves in Proposition 1 leads to the following equilibrium requirement

$$
\Psi_{I}\left(\theta_{I} ; \Phi_{I}\right) \equiv \Phi_{I}\left(b-\frac{\sigma-1}{\sigma-\beta}\right)+\frac{c}{1-\beta}\left(\frac{r+s}{m\left(\theta_{I}\right)(1-\delta)}+\frac{\beta \theta_{I}}{1-\delta}\right)=0 .
$$

Differentiating $\Psi_{I}\left(\theta_{I} ; \Phi_{I}\right)$ with respect to $\Phi_{I}$ and $\theta_{I}$ yields

$$
\frac{\partial \theta_{I}}{\partial \Phi_{I}}=-\frac{\partial \Psi_{I}\left(\theta_{I} ; \Phi_{I}\right) / \partial \Phi_{I}}{\partial \Psi_{I}\left(\theta_{I} ; \Phi_{I}\right) / \partial \theta_{I}}=-\frac{b-\frac{\sigma-1}{\sigma-\beta}}{\frac{c}{1-\beta}\left(-\frac{r+s}{1-\delta} \frac{m^{\prime}\left(\theta_{I}\right)}{m\left(\theta_{I}\right)^{2}}+\frac{\beta}{1-\delta}\right)}>0,
$$

when the requirement for equilibrium existence $b<\frac{\sigma-1}{\sigma-\beta}$ is satisfied.

Proof of Proposition 2. The contract curve is given by the points where the firm iso-profit curves are tangent to the union's indifference curves, so that

$$
\frac{\partial \mathbf{F}\left(l_{C}, w_{C} ; \varphi\right) / \partial l_{C}}{\partial \mathbf{F}\left(l_{C}, w_{C} ; \varphi\right) / \partial w_{C}}=\frac{\partial \mathbf{U}\left(l_{C}, w_{C} ; \varphi\right) / \partial l_{C}}{\partial \mathbf{U}\left(l_{C}, w_{C} ; \varphi\right) / \partial w_{C}} \Rightarrow \frac{\partial R\left(l_{C} ; \varphi\right)}{\partial l_{C}}=r U_{C}+\left(\frac{r+s}{1-\delta}\right) \frac{c}{m\left(\theta_{C}\right)} .
$$


The actual contract solves the following Nash-bargaining problem ${ }^{40}$

$$
\max _{w_{C}, l_{C}} \Omega\left(w_{C}, l_{C} ; \varphi\right) \equiv \mathbf{U}\left(l_{C}, w_{C} ; \varphi\right)^{\beta} \mathbf{F}\left(l_{C}, w_{C} ; \varphi\right)^{1-\beta}
$$

The union and the firm split the forward looking surplus. ${ }^{41}$ The first order condition with respect to the wage rate is

$$
w_{C}\left(\varphi, l_{C}\right)=(1-\beta) r U_{C}+\beta\left[\frac{R\left(l_{C} ; \varphi\right)}{l_{C}}-\left(\frac{r+s}{1-\delta}\right) \frac{c}{m\left(\theta_{C}\right)}\right]=r U_{C}+\left(\frac{\beta}{\sigma}\right) \frac{R\left(l_{C} ; \varphi\right)}{l_{C}},
$$

where the second equality is obtained substituting the Pareto optimality condition (30) and using the identity $\partial R\left(l_{C} ; \varphi\right) / \partial l_{C}=\left(\frac{\sigma-1}{\sigma}\right) R\left(l_{C} ; \varphi\right) / l_{C}$. Equation $(32)$ is the Wage curve under collective bargaining. The Job Creation curve is given by the first order condition of problem (31) with respect to the employment level

$$
w_{C}\left(\varphi, l_{C}\right)=\left(1-\frac{1-\beta}{\sigma}\right) \frac{R\left(l_{C} ; \varphi\right)}{l_{C}}-\left(\frac{r+s}{1-\delta}\right) \frac{c}{m\left(\theta_{C}\right)} .
$$

Both conditions indicate that wages are identical across firms since, as explained in the proof of Proposition $1, R\left(l_{C} ; \varphi\right) / l_{C}=p_{D}(\varphi) \varphi=p_{D}(\tilde{\varphi}) \tilde{\varphi}=M_{C}^{\frac{\nu}{\sigma-1}} \tilde{\varphi}$. The employees' outside option therefore reads

$$
r U_{C}\left(\theta_{C}\right)=b+\theta_{C} m\left(\theta_{C}\right)\left(\frac{w_{C}-r U_{C}}{r+s}\right)=b+\theta_{C} m\left(\theta_{C}\right)\left(\frac{\beta}{\sigma(r+s)}\right) \Phi_{C},
$$

where the last equality follows from (32). Combining the three equations above, yields the expressions in Proposition 2. The existence and uniqueness requirements follow from the same reasoning than in the proof of Proposition 1.

Proof of Corollary 2. The proof is established in a similar fashion as Corollary 1. Combining the Job Creation and Wage curves in Proposition 2 leads to the following equilibrium requirement

$$
\Psi_{C}\left(\theta_{C} ; \Phi_{C}\right) \equiv \Phi_{C}\left(b+\frac{\beta}{\sigma}\left(\frac{\theta_{C} m\left(\theta_{C}\right)+r+s}{r+s}\right)+\frac{-\sigma+1-\beta}{\sigma}\right)+\left(\frac{r+s}{1-\delta}\right) \frac{c}{m\left(\theta_{C}\right)}=0 .
$$

Differentiating $\Psi_{C}\left(\theta_{C} ; \Phi_{C}\right)$ with respect to $\Phi_{C}$ and $\theta_{C}$ yields

$$
\frac{\partial \theta_{C}}{\partial \Phi_{C}}=-\frac{\partial \Psi_{C}\left(\theta_{C} ; \Phi_{C}\right) / \partial \Phi_{C}}{\partial \Psi_{C}\left(\theta_{C} ; \Phi_{C}\right) / \partial \theta_{C}}>0
$$

${ }^{40}$ The set-up cost $F$ is sunk and so cannot be recovered by the firm in case of disagreement with the union. Thus it does not enter the firm outside option. If one assume, as in Melitz (2003), that operating costs are paid in each period, the strategic form of the Nash-bargaining problem still holds as long as the firm cannot default on his payment following a breakdown in the wage negotiation. Notice, however, that when fixed costs are included in the firm threat point, the solution to (31) does not lie on the contract curve and so violates the axiom of Pareto optimality. Hence, our formulation can also be justified on axiomatic ground.

${ }^{41}$ Considering instead that disagreement delays production does not fundamentally affect our result. 
The inequality sign follows from

$$
\begin{aligned}
& \frac{\partial \Psi_{C}\left(\theta_{C} ; \Phi_{C}\right)}{\partial \Phi_{C}}=b+\frac{\beta}{\sigma} \frac{\theta_{C} m\left(\theta_{C}\right)+r+s}{r+s}+\frac{-\sigma+1-\beta}{\sigma}=-\frac{1}{\Phi_{C}}\left[\left(\frac{r+s}{1-\delta}\right) \frac{c}{m\left(\theta_{C}\right)}\right]<0 \\
& \frac{\partial \Psi_{C}\left(\theta_{C} ; \Phi_{C}\right)}{\partial \theta_{C}}=\frac{\Phi_{C} \beta\left[\theta_{C} m^{\prime}\left(\theta_{C}\right)+m\left(\theta_{C}\right)\right]}{\sigma(r+s)}-\left(\frac{r+s}{1-\delta}\right) \frac{c m^{\prime}\left(\theta_{C}\right)}{m\left(\theta_{C}\right)^{2}}>0
\end{aligned}
$$

The last equality follows from $\Psi_{C}\left(\theta_{C} ; \tilde{\varphi}_{C}\right)=0$ and the sign of the inequality holds true due to the homogeneity of degree one of the matching function.

Proof of Lemma 1. We first establish that the relationship between $\varphi_{D}^{*}$ and $\varphi_{X}^{*}$ does not depend on $\theta$. From the definition of the cutoff productivity in equation (15)

$$
\pi_{X}\left(\varphi_{X}^{*}\right)+f_{X}-\left(\frac{r+\delta}{1-\delta}\right) \frac{c}{m(\theta)} l_{X}\left(\varphi_{X}^{*}\right)=\tau^{1-\sigma}\left[\pi_{D}\left(\varphi_{X}^{*}\right)+f_{D}-\left(\frac{r+\delta}{1-\delta}\right) \frac{c}{m(\theta)} l_{D}\left(\varphi_{X}^{*}\right)\right]=\left(\frac{r+\delta}{1-\delta}\right) f_{X} .
$$

But we also know that employment levels are $\log$-linear functions of $\varphi$, so that

$$
\begin{aligned}
\pi_{D}\left(\varphi_{X}^{*}\right)+f_{D}-\left(\frac{r+\delta}{1-\delta}\right) \frac{c}{m(\theta)} l_{D}\left(\varphi_{X}^{*}\right) & =\left(\frac{\varphi_{X}^{*}}{\varphi_{D}^{*}}\right)^{\sigma-1}\left[\pi_{D}\left(\varphi_{D}^{*}\right)+f_{D}-\left(\frac{r+\delta}{1-\delta}\right) \frac{c}{m(\theta)} l_{D}\left(\varphi_{D}^{*}\right)\right] \\
& =\left(\frac{\varphi_{X}^{*}}{\varphi_{D}^{*}}\right)^{\sigma-1}\left(\frac{r+\delta}{1-\delta}\right) f_{D},
\end{aligned}
$$

where the last equality follows from the definition of $\varphi_{D}^{*}$. Combining the two relations above, yields the same relationship than in Melitz (2003): $\varphi_{X}^{*}=\tau \varphi_{D}^{*}\left(f_{X} / f_{D}\right)^{\frac{1}{\sigma-1}}$. This equation allow us to use (19) to pin down $\varphi_{D}^{*}$. We can then use (14) to express $\tilde{\varphi}_{k}$ as a function of $\varphi_{k}^{*}$, for $k \in\{D, X\}$.

Proof of Lemma 2. We derive the equilibrium mass of firms when wages are bargained at the individual level. The average levels of employment follow from the requirement that the profits of $\varphi_{D}^{*}$-firms be zero

$$
l_{k}\left(\varphi_{k}^{*}\right)\left[\left(\Phi_{C}-w\right) \frac{1-\delta}{r+\delta}-\frac{c}{m(\theta)} \frac{r+s}{r+\delta}\right]=f_{D}\left(\frac{1+r}{r+\delta}\right), \text { for } k \in\{D, X\}
$$

and the log-linear relation between firm sizes: $l_{k}(\tilde{\varphi})=\left(\tilde{\varphi}_{k} / \varphi_{k}^{*}\right)^{\sigma-1} l_{k}\left(\varphi_{k}^{*}\right)$, for $k \in\{D ; X\}$. Reinserting the job creation curve yields

$$
l_{k}\left(\tilde{\varphi}_{k}\right)=\left(\frac{\tilde{\varphi}_{k}}{\varphi_{k}^{*}}\right)^{\sigma-1}\left(\frac{1+r}{1-\delta}\right)\left(\frac{\sigma-\beta}{1-\beta}\right) \frac{f_{k}}{M^{\frac{\nu}{\sigma-1}} \tilde{\varphi}}, \text { for } k \in\{D, X\} .
$$

Accordingly, equation (21) is equivalent to

$$
M_{I, D}=L\left(\frac{\theta m\left(\theta_{I}\right)}{s+\theta m\left(\theta_{I}\right)}\right)\left(\frac{1-\beta}{\sigma-\beta}\right)\left(\frac{1-\delta}{1+r}\right)\left[\left(\frac{\tilde{\varphi}_{D}}{\varphi_{D}^{*}}\right)^{\sigma-1}\left(\frac{f_{D}}{M_{I}^{\frac{\nu}{\sigma-1}} \tilde{\varphi}}\right)+n \varrho\left(\frac{\tilde{\varphi}_{X}}{\varphi_{X}^{*}}\right)^{\sigma-1}\left(\frac{f_{X}}{M_{I}^{\frac{\nu}{\sigma-1}} \tilde{\varphi}}\right)\right]^{-1},
$$


Using the Free Entry condition (19), we can rearrange this expression as follows

$$
M_{I, D}=M_{I}^{\frac{\nu}{\sigma-1}} \tilde{\varphi} L\left(\frac{\theta_{I} m\left(\theta_{I}\right)}{s+\theta_{I} m\left(\theta_{I}\right)}\right)\left(\frac{1-\beta}{\sigma-\beta}\right)\left(\frac{1-\delta}{1+r}\right)\left[\left(\frac{r+\delta}{1+r}\right) \frac{f_{E}}{1-G\left(\varphi_{D}^{*}\right)}+f_{D}+n \varrho f_{X}\right]^{-1} .
$$

In order to get the final solution for the number of available varieties, one has to take $M_{I}=(1+n \varrho) M_{I, D}$ into consideration, so that

$$
\begin{aligned}
M_{I} & =(1+n \varrho) M_{I}^{\frac{\nu}{\sigma-1}} \tilde{\varphi} L\left(\frac{\theta_{I} m\left(\theta_{I}\right)}{s+\theta_{I} m\left(\theta_{I}\right)}\right)\left(\frac{1-\beta}{\sigma-\beta}\right)\left(\frac{1-\delta}{r+s}\right)\left[\left(\frac{r+\delta}{1+r}\right) \frac{f_{E}}{1-G\left(\varphi_{D}^{*}\right)}+f_{D}+n \varrho f_{X}\right]^{-1} \\
& =\left[(1+n \varrho) L\left(\frac{\theta_{I} m\left(\theta_{I}\right)}{s+\theta_{I} m\left(\theta_{I}\right)}\right)\left(\frac{1-\beta}{\sigma-\beta}\right)\left(\frac{1-\delta}{r+s}\right)\left(\frac{\tilde{\varphi}}{\left(\frac{r+\delta}{1+r}\right) \frac{f_{E}}{1-G\left(\varphi_{D}^{*}\right)}+f_{D}+n \varrho f_{X}}\right)\right]^{\frac{1-\sigma}{1-\sigma+\nu}} .
\end{aligned}
$$

The solution in the case where wages are collectively bargaining is obtained following the same steps.

Proof of Proposition 3(i). The definition of $\tilde{\varphi}$ in equation (13) and the equilibrium condition (19) imply that

$$
\tilde{\varphi}=\varphi_{D}^{*}\left\{\frac{1}{1+n \varrho}\left[\left(\frac{\tilde{\varphi}_{D}}{\varphi_{D}^{*}}\right)^{\sigma-1}+n \varrho \frac{f_{X}}{f_{D}}\left(\frac{\tilde{\varphi}_{X}}{\varphi_{X}^{*}}\right)^{\sigma-1}\right]\right\}^{\frac{1}{\sigma-1}}=\varphi_{D}^{*}\left[\frac{\frac{f_{E} / f_{D}}{1-G\left(\varphi_{D}^{*}\right)}\left(\frac{1+r}{r+\delta}\right)+1+n \varrho \frac{f_{X}}{f_{D}}}{1+n \varrho}\right]^{\frac{1}{\sigma-1}}
$$

As explained in Melitz, trade liberalization always raises $\varphi_{D}^{*}$ as it shifts up the Zero Cutoff Profit condition but leaves the Free Entry condition unchanged. Hence $\partial\left(\frac{1+n \varrho \frac{f_{X}}{f_{D}}}{1+n \varrho}\right) / \partial n \geq 0 \Rightarrow \partial \tilde{\varphi} / \partial n \geq 0$, which obviously holds true when $f_{X} \geq f_{D}$. A similar result can be derived for $\tau$ noticing that $\partial \varrho / \partial \tau<0$. On the other hand, $f_{X}$ has two opposite effects: it reduces the share of exporting firms $\varrho$ and it increases the ratio $\left\{f_{X} / f_{D}\right\}$. Thus, even when $f_{X}>f_{D}$, the effect of $f_{X}$ is a priori ambiguous. The effect of trade liberalization on unemployment stated in Proposition 3(i) immediately follows from Corollaries 1 and 2 and the fact that, since $(1-\nu)=1, M^{\frac{\nu}{\sigma-1}}=1$ for all $M>0$. Given that the Wage curve in both bargaining regimes is increasing in $\theta$, it also follows that real wages are increasing in $n$ and $\tau$.

Proof of Proposition 3(ii). Because there does not exist a general closed-form solution for $\varphi_{D}^{*}$, we have to impose a particular functional form on $g(\varphi)$ in order to derive necessary conditions which are functions of the exogenous parameters. We follow the common practice in the literature by considering that $g(\varphi)$ is Pareto, so that $g(\varphi)=\frac{\gamma}{\varphi}\left(\frac{\bar{\varphi}}{\varphi}\right)^{\gamma}$. Since the absolute value of $\varphi$ is meaningless in our model, we can normalize $\bar{\varphi}$ to one without loss of generality. Then it holds true that

$$
\tilde{\varphi}_{D}=\left(\frac{\gamma}{1-\sigma+\gamma}\right)^{\frac{1}{\sigma-1}} \varphi_{D}^{*} \quad \text { and } \quad \tilde{\varphi}_{X}=\left(\frac{\gamma}{1-\sigma+\gamma}\right)^{\frac{1}{\sigma-1}} \varphi_{X}^{*}
$$


and $\tilde{\varphi}$ can be decomposed as follows

$$
\tilde{\varphi}=\left[\frac{1}{1+n \varrho}\left(\tilde{\varphi}_{D}^{\sigma-1}+n \varrho \tau^{1-\sigma} \tilde{\varphi}_{X}^{\sigma-1}\right)\right]^{\frac{1}{\sigma-1}}=\left(\frac{\gamma}{1-\sigma+\gamma}\right)^{\frac{1}{\sigma-1}} \varphi_{D}^{*}\left[\frac{1+n \varrho\left(\frac{f_{X}}{f_{D}}\right)}{1+n \varrho}\right]^{\frac{1}{\sigma-1}} .
$$

We can now use the equilibrium condition (19) to express $\varphi_{D}^{*}$ as a function of the parameters

$$
\begin{aligned}
\varphi_{D}^{*} & =\left[\left(\frac{1}{f_{E}}\right)\left(\frac{1+r}{r+\delta}\right)\left\{f_{D}\left[\left(\frac{\tilde{\varphi}_{D}}{\varphi_{D}^{*}}\right)^{\sigma-1}-1\right]+n \varrho f_{X}\left[\left(\frac{\tilde{\varphi}_{X}}{\varphi_{X}^{*}}\right)^{\sigma-1}-1\right]\right\}\right]^{\frac{1}{\gamma}} \\
& =\left[\left(\frac{f_{D}}{f_{E}}\right)\left(\frac{1+r}{r+\delta}\right)\left(\frac{\gamma}{1-\sigma+\gamma}-1\right)\left(1+n \varrho\left(\frac{f_{X}}{f_{D}}\right)\right)\right]^{\frac{1}{\gamma}} .
\end{aligned}
$$

Reinserting this expression into (38) and using the fact that $\varrho=\tau^{-\gamma}\left(f_{D} / f_{X}\right)^{\frac{\gamma}{\sigma-1}}$, we finally obtain

$$
\tilde{\varphi}=K_{0}\left(1+n \tau^{-\gamma}\left(f_{D} / f_{X}\right)^{\frac{\gamma-\sigma+1}{\sigma-1}}\right)^{\frac{1}{\sigma-1}+\frac{1}{\gamma}}\left(1+n \tau^{-\gamma}\left(f_{D} / f_{X}\right)^{\frac{\gamma}{\sigma-1}}\right)^{-\frac{1}{\sigma-1}}
$$

where

$$
K_{0} \equiv\left(\frac{\gamma}{1-\sigma+\gamma}\right)^{\frac{1}{\sigma-1}}\left[\left(\frac{f_{D}}{f_{E}}\right)\left(\frac{1+r}{r+\delta}\right)\left(\frac{\sigma-1}{1-\sigma+\gamma}\right)\right]^{\frac{1}{\gamma}} .
$$

Differentiating this expression with respect to $n$ shows that

$$
\frac{\partial \tilde{\varphi}}{\partial n} \geq 0 \Leftrightarrow \frac{\sigma-1}{\gamma}\left(1+n \tau^{-\gamma}\left(f_{D} / f_{X}\right)^{\frac{\gamma}{\sigma-1}}\right) \geq \frac{f_{D}}{f_{X}}-1 .
$$

Since $f_{X} \tau^{\sigma-1}>f_{D}$, it is easily seen that: $\frac{\sigma-1}{\gamma}(1+n) \leq \frac{f_{D}}{f_{X}}-1 \Rightarrow \partial \tilde{\varphi} / \partial n<0$. This establishes that the necessary condition above can be violated. The effects of $\tau$ is easily derived following similar steps. Regarding the comparative static with respect to $f_{X}$, we have

$$
\frac{\partial \tilde{\varphi}}{\partial f_{X}} \leq 0 \Leftrightarrow\left(\frac{\gamma}{\sigma-1}\right)^{2} \geq \frac{f_{X}}{f_{X}-f_{D}}\left[1+n \tau^{-\gamma}\left(\frac{f_{X}}{f_{D}}\right)^{-\frac{\gamma}{\sigma-1}}\right]
$$

Clearly, that inequality can hold only if $f_{X}>f_{D}$.

The impact on employment and real wages is obtained from the same reasoning than in the proof of Proposition 3(i).

\section{Proof of Lemma 3}

Individual Bargaining. It is easily seen that, when $\sigma+(1-\nu)>2$, both (22) and (24) converge to zero as $\theta_{I}$ goes to zero. When $\theta_{I}$ goes to infinity, (24) diverges to infinity whereas (22) converges to

$$
\bar{M} \equiv\left[L(1+n \varrho)\left(\frac{1-\beta}{\sigma-\beta}\right)\left(\frac{1-\delta}{r+s}\right)\left(\frac{\tilde{\varphi}_{I}}{\left(\frac{r+\delta}{1+r}\right) \frac{f_{E}}{1-G\left(\varphi_{D}^{*}\right)}+f_{D}+n \varrho f_{X}}\right)\right]^{\frac{1-\sigma}{1-\sigma+\nu}}<\infty .
$$


Hence, the existence of an equilibrium is established if the derivative of (24) at $\theta_{I}=0$ is inferior to that of (22). Since

$$
\left.\frac{\partial M_{I}}{\partial \theta_{I}}\right|_{E T C_{I}}=\frac{\sigma-1}{\nu} K_{1}\left(\frac{r+s+\beta \theta_{I} m\left(\theta_{I}\right)}{m\left(\theta_{I}\right)}\right)^{\frac{\sigma-1}{\nu}-1}\left(\frac{\alpha(r+s)+\beta \theta_{I} m\left(\theta_{I}\right)}{\theta_{I} m\left(\theta_{I}\right)}\right),
$$

with $K_{1} \equiv\left[c\left((1-\beta)(1-\delta) \tilde{\varphi}\left(\frac{\sigma-1}{\sigma-\beta}-b\right)\right)^{-1}\right]^{\frac{\sigma-1}{\nu}}$, the derivative of $(22)$ w.r.t. $\theta_{I}$ converges to zero as $\theta_{I}$ goes to zero if and only if: $\lim _{\theta_{I} \rightarrow 0} \theta_{I} m\left(\theta_{I}\right)^{\frac{\sigma-1}{\nu}}=\infty$. With the Cobb-Douglas specification, this requirement is fulfilled when $\alpha>\frac{\nu}{\sigma-1}$. Consider now the derivative of (22) w.r.t. $\theta_{I}$

$$
\left.\frac{\partial M_{I}}{\partial \theta_{I}}\right|_{L M C_{I}}=\frac{\sigma-1}{\sigma-1-\nu} K_{2}\left(\frac{\theta_{I} m\left(\theta_{I}\right)}{s+\theta_{I} m\left(\theta_{I}\right)}\right)^{\frac{1-\sigma}{1-\sigma+\nu}-1}\left(\frac{(1-\alpha) m\left(\theta_{I}\right) s}{\left(s+\theta_{I} m\left(\theta_{I}\right)\right)^{2}}\right),
$$

where

$$
K_{2} \equiv\left[L(1+n \varrho)\left(\frac{1-\beta}{\sigma-\beta}\right)\left(\frac{1-\delta}{r+s}\right)\left(\frac{\tilde{\varphi}}{\left(\frac{r+\delta}{1+r}\right) \frac{f_{E}}{1-G\left(\varphi_{D}^{*}\right)}+f_{D}+n \varrho f_{X}}\right)\right]^{\frac{1-\sigma}{1-\sigma+\nu}} .
$$

Hence it diverges to infinity as $\theta$ goes to zero if and only if: $\lim _{\theta \rightarrow 0} \theta^{\frac{1-\sigma}{1-\sigma+\nu}-1} m(\theta)^{\frac{1-\sigma}{1-\sigma+\nu}}=\infty$. With the Cobb-Douglas specification, this requirement is fulfilled when $\alpha>\frac{\nu}{\sigma-1}$. Hence, equilibrium existence is established.

The uniqueness of the equilibrium follows from the fact that (24) is convex while (22) is concave in $\theta_{I}$. Since

$$
\left.\frac{\partial^{2} M_{I}}{\partial \theta_{I}^{2}}\right|_{E T C_{I}}=K_{1}\left(\frac{\sigma-1}{\nu}\right)\left[Z_{1}-Z_{2}\right]
$$

where

$$
\begin{aligned}
& Z_{1}=\left(\frac{\sigma-1}{\nu}-1\right)\left((r+s) m_{0}^{-1} \theta_{I}^{\alpha}+\beta \theta_{I}\right)^{\frac{\sigma-1}{\nu}-2}\left(\alpha(r+s) m_{0}^{-1} \theta_{I}^{\alpha-1}+\beta\right)^{2}, \\
& Z_{2}=(1-\alpha)\left((r+s) m_{0}^{-1} \theta_{I}^{\alpha}+\beta \theta_{I}\right)^{\frac{\sigma-1}{\nu}-1} \alpha(r+s) m_{0}^{-1} \theta_{I}^{\alpha-2} .
\end{aligned}
$$

The second derivative of (24) is positive when

$$
Z_{1}>Z_{2} \Leftrightarrow\left(\frac{\sigma-1}{\nu}-1\right)\left(\alpha(r+s) m_{0}^{-1} \theta_{I}^{\alpha-1}+\beta\right)^{2}>(1-\alpha)\left((r+s) m_{0}^{-1} \theta^{\alpha}+\beta \theta_{I}\right) \alpha(r+s) m_{0}^{-1} \theta_{I}^{\alpha-2} .
$$

But the term on the left-hand side of the inequality can be lower-bounded as follows

$$
\begin{aligned}
\left(\frac{\sigma-1}{\nu}-1\right)\left(\alpha(r+s) m_{0}^{-1} \theta_{I}^{\alpha-1}+\beta\right)^{2} & >\left(\frac{\sigma-1}{\nu}-1\right) \alpha^{2}\left((r+s) m_{0}^{-1} \theta_{I}^{\alpha-1}+\beta\right)^{2} \\
& >\left(\frac{\sigma-1}{\nu}-1\right) \alpha\left((r+s) m_{0}^{-1} \theta_{I}^{\alpha}+\beta \theta_{I}\right) \alpha(r+s) m_{0}^{-1} \theta_{I}^{\alpha-2}
\end{aligned}
$$


Thus (24) is convex when $\left(\frac{\sigma-1}{\nu}-1\right) \alpha>1-\alpha \Leftrightarrow \alpha>\frac{\nu}{\sigma-1}$. Similarly differentiating twice (22) w.r.t. $\theta_{I}$ yields

$$
\left.\frac{\partial^{2} M_{I}}{\partial \theta_{I}^{2}}\right|_{L M C_{I}}=\frac{K_{2} \frac{(1-\sigma)(1-\alpha)}{1-\sigma+\nu} s}{\left(s+m_{0} \theta_{I}^{1-\alpha}\right)^{2\left(\frac{1-\sigma}{1-\sigma+\nu}+1\right)}}\left[Z_{3}-Z_{4}\right]
$$

where

$$
\begin{aligned}
& Z_{3}=\left(\frac{(1-\sigma)(1-\alpha)}{1-\sigma+\nu}-1\right) m_{0}^{\frac{1-\sigma}{1-\sigma+\nu}} \theta_{I}^{\frac{(1-\sigma)(1-\alpha)}{1-\sigma+\nu}-2}\left(s+m_{0} \theta_{I}^{1-\alpha}\right)^{\frac{1-\sigma}{1-\sigma+\nu}+1}, \\
& Z_{4}=\left(\frac{1-\sigma}{1-\sigma+\nu}+1\right)(1-\alpha) m_{0}^{\frac{1-\sigma}{1-\sigma+\nu}+1} \theta_{I}^{\frac{(1-\sigma)(1-\alpha)}{1-\sigma+\nu}-\alpha-1}\left(s+m_{0} \theta_{I}^{1-\alpha}\right)^{\frac{1-\sigma}{1-\sigma+\nu}},
\end{aligned}
$$

which is negative when $\frac{(1-\sigma)(1-\alpha)}{1-\sigma+\nu}<1 \Leftrightarrow \alpha>\frac{\nu}{\sigma-1}$.

Collective Bargaining. The $E T C_{C}$ is well defined only if

$$
\frac{\sigma-1}{\sigma}-b>\frac{\beta}{\sigma} \frac{\theta_{C} m\left(\theta_{C}\right)}{r+s} \Leftrightarrow \frac{\sigma-1}{\sigma}-b=\Upsilon \frac{\beta}{\sigma} \frac{\theta_{C} m\left(\theta_{C}\right)}{r+s},
$$

which makes sure that the equilibrium mass is real-valued and from where it follows that $\Upsilon>1$. This restriction allows to find a sufficient condition for the strict convexity of $E T C_{C}$, very much in line with the proof for Individual bargaining.

It is easily seen that (22) and (24) converge to zero as $\theta$ goes to zero. When $\theta$ goes to the upper bound $\bar{\theta}_{C},(25)$ diverges to infinity whereas (23) converges to some $\bar{M}_{C}<\infty$. Under collective bargaining the first derivative of the $E T C_{C}$ with respect to $\theta_{C}$ is

$$
\left.\frac{\partial M_{C}}{\partial \theta_{C}}\right|_{E T C_{C}}=\frac{\sigma-1}{\nu} \frac{\left[\left(\frac{r+s}{1-\delta}\right) \frac{c}{m_{0}}\right]^{\frac{\sigma-1}{\nu}}\left(Z_{5}+Z_{6}\right)}{\tilde{\varphi}^{\frac{\sigma-1}{\nu}}\left(\frac{\sigma-1}{\sigma}-b-\frac{\beta}{\sigma} \frac{m_{0} \theta_{C}^{1-\alpha}}{r+s}\right)^{\frac{\sigma-1}{\nu}+1}}
$$

where

$$
\begin{aligned}
& Z_{5}=\left\{\alpha\left[\left(\frac{\sigma-1}{\sigma}-b\right) \theta_{C}^{\alpha \frac{\sigma-1}{\nu}-1}-\frac{\beta}{\sigma} \frac{m_{0}}{r+s} \theta_{C}^{\alpha\left(\frac{\sigma-1}{\nu}-1\right)}\right]\right\}, \\
& Z_{6}=\left\{(1-\alpha) \frac{\beta}{\sigma} \frac{m_{0}}{r+s} \theta_{C}^{\alpha\left(\frac{\sigma-1}{\nu}-1\right)}\right\},
\end{aligned}
$$

which converges to zero if $\theta$ goes to zero if $\alpha>\frac{\nu}{\sigma-1}$. The slope of $L M C_{C}$ in $\theta_{C}$ depends on the same conditions than $L M C_{I}$. The $L M C_{C}$ is strictly concave (the proof is identical to the case of individual bargaining). The strict convexity of $E T C_{C}$ requires

$$
\left.\frac{\partial^{2} M_{C}}{\partial \theta_{C}^{2}}\right|_{E T C_{C}}=\frac{\sigma-1}{\nu} \frac{1}{\tilde{\varphi}^{\frac{\sigma-1}{\nu}}} \frac{\left[\left(\frac{r+s}{1-\delta}\right) \frac{c}{m_{0}}\right]^{\frac{\sigma-1}{\nu}}\left\{\left(Z_{5}^{\prime}+Z_{6}^{\prime}\right) Z_{7}-\left(Z_{5}+Z_{6}\right) Z_{7}^{\prime}\right\}}{Z_{7}^{2}}>0
$$


where $Z_{7}=\left(\frac{\sigma-1}{\sigma}-b-\frac{\beta}{\sigma} \frac{m_{0} \theta_{C}^{1-\alpha}}{r+s}\right)^{\frac{\sigma-1}{\nu}+1}$ and

$$
\begin{aligned}
& Z_{5}^{\prime}=\left\{\alpha\left[\left(\alpha \frac{\sigma-1}{\nu}-1\right)\left(\frac{\sigma-1}{\sigma}-b\right) \theta_{C}^{\alpha \frac{\sigma-1}{\nu}-2}-\left(\alpha\left(\frac{\sigma-1}{\nu}-1\right)\right) \frac{\beta}{\sigma} \frac{m_{0}}{r+s} \theta_{C}^{\alpha\left(\frac{\sigma-1}{\nu}-1\right)-1}\right]\right\}, \\
& Z_{6}^{\prime}=\left\{(1-\alpha) \alpha\left(\frac{\sigma-1}{\nu}-1\right) \frac{\beta}{\sigma} \frac{m_{0}}{r+s} \theta_{C}^{\alpha\left(\frac{\sigma-1}{\nu}-1\right)-1}\right\}, \\
& Z_{7}^{\prime}=-(1-\alpha)\left(\frac{\sigma-1}{\nu}+1\right)\left(\frac{\sigma-1}{\sigma}-b-\frac{\beta}{\sigma} \frac{m_{0} \theta_{C}^{1-\alpha}}{r+s}\right)^{\frac{\sigma-1}{\nu}}\left(\frac{\beta}{\sigma} \frac{m_{0} \theta_{C}^{-\alpha}}{r+s}\right) .
\end{aligned}
$$

The second derivative is positive when $Z_{5}^{\prime}+Z_{6}^{\prime}$ is positive which holds if

$$
\alpha\left(\alpha \frac{\sigma-1}{\nu}-1\right)\left(\frac{\sigma-1}{\sigma}-b\right) \theta_{C}^{\alpha \frac{\sigma-1}{\nu}-1}+(1-2 \alpha)\left(\alpha\left(\frac{\sigma-1}{\nu}-1\right)\right) \frac{\beta}{\sigma} \frac{m_{0}}{r+s} \theta_{C}^{\alpha\left(\frac{\sigma-1}{\nu}-1\right)}>0 .
$$

which is positive if $\alpha>\frac{\nu}{\sigma-1}$ and $\sigma>2$. This condition can be lower bounded using (45). Thus we know that the second derivative is positive as long as the following condition holds

$$
\alpha\left(\alpha \frac{\sigma-1}{\nu}-1\right) \Upsilon+(1-2 \alpha)\left(\alpha\left(\frac{\sigma-1}{\nu}-1\right)\right)>0
$$

Let $\Upsilon \rightarrow 1$, then $(\sigma-1) / \nu>2$ secures that the the second derivative is positive. Hence, the equilibrium is unique if $\frac{\nu}{\sigma-1}<\min \left[\alpha, \frac{1}{2}\right]$.

Proof of Proposition 4(i) Interacting equations (24) and (22), and the proof in Lemma 3 that (24) intersects (22) from below, it can be seen that

$$
\operatorname{sign}\left\{\frac{\partial \theta}{\partial n}\right\}=\operatorname{sign}\left\{\frac{\partial\left[\tilde{\varphi}^{\frac{(\sigma-1)^{2}}{(\sigma-1-\nu) \nu}}(1+n \varrho)^{\frac{1-\sigma}{1-\sigma+\nu}}\left[\left(\frac{r+\delta}{1+r}\right) \frac{f_{E} / f_{D}}{1-G\left(\varphi_{D}^{*}\right)}+1+n \varrho\left(f_{X} / f_{D}\right)\right]^{\frac{\sigma-1}{1-\sigma+\nu}}\right]}{\partial n}\right\} .
$$

According to the definition of $\tilde{\varphi}$ in (37), the term on the right-hand side reads

$$
\tilde{\varphi}^{\frac{(\sigma-1)^{2}}{(\sigma-1-\nu) \nu}}\left[\frac{1+n \varrho}{\left(\frac{r+\delta}{1+r}\right) \frac{f_{E} / f_{D}}{1-G\left(\varphi_{D}^{*}\right)}+1+n \varrho\left(f_{X} / f_{D}\right)}\right]^{\frac{1-\sigma}{1-\sigma+\nu}}=\varphi_{D}^{* \lambda 1}\left[\frac{\left(\frac{r+\delta}{1+r}\right) \frac{f_{E} / f_{D}}{1-G\left(\varphi_{D}^{*}\right)}+1+n \varrho\left(f_{X} / f_{D}\right)}{1+n \varrho}\right]^{\lambda 2},
$$

where

$$
\lambda_{1}=\frac{(\sigma-1)^{2}}{\nu(\sigma-1-\nu)}>0 \text { and } \lambda_{2}=\frac{(1-\nu)(\sigma-1)}{\nu(\sigma-1-\nu)}>0 .
$$

We know from Melitz (2003) that $\varphi_{D}^{*}$ is increasing in $n$. Hence, the number of trading partners unambiguously raises the vacancy-unemployment ratio when $f_{x}>f_{D}$. As before, a similar prediction can be derived for $\tau$ noticing that $\partial \varrho / \partial \tau<0$, whereas the effect of $f_{X}$ is a priori ambiguous. 
Proof of Proposition 4(ii) When firms draw their productivities from a Pareto distribution, we can use (39) to substitute $\varphi_{D}^{*}$ in condition (48). Since $\varrho$ can be replaced by $\tau^{-\gamma}\left(f_{D} / f_{X}\right)^{\frac{\gamma}{\sigma-1}}$, we obtain

$$
\operatorname{sign}\left\{\frac{\partial \theta}{\partial n}\right\}=\operatorname{sign}\left\{\frac{\partial\left[\left(1+n \tau^{-\gamma}\left(f_{D} / f_{X}\right)^{\frac{\gamma}{\sigma-1}}\right)^{-\lambda 2}\left(1+n \tau^{-\gamma}\left(f_{D} / f_{X}\right)^{\frac{\gamma-\sigma+1}{\sigma-1}}\right)^{\lambda 2+\lambda 1 / \gamma}\right]}{\partial n}\right\} .
$$

Differentiating this expression with respect to $n$ shows that

$$
\frac{\partial \theta}{\partial n} \geq 0 \Leftrightarrow\left(\frac{\sigma-1}{\gamma(1-\nu)}\right)\left(1+n \tau^{-\gamma}\left(f_{D} / f_{X}\right)^{\frac{\gamma}{\sigma-1}}\right) \geq \frac{f_{D}}{f_{X}}-1
$$

Obviously, this condition is always satisfied when $(1-\nu)=0$, as in Melitz (2003). A similar result follows for $\tau$. An increase in foreign beachhead costs leads to a decreasing average productivity if the following requirement is fulfilled

$$
\frac{\partial \theta}{\partial f_{X}} \leq 0 \Leftrightarrow \frac{\gamma^{2}(1-\nu)}{(\sigma-1)((\sigma-1)-\nu \gamma)} \geq \frac{f_{X}}{f_{X}-f_{D}}\left[1+n \tau^{-\gamma}\left(\frac{f_{D}}{f_{X}}\right)^{\frac{\gamma}{\sigma-1}}\right]
$$

\section{B Additional simulation results}

Individual bargaining

\begin{tabular}{l|l|rrrr|rrrr} 
& $f_{X}$ & 22.5 & 38.25 & 65.025 & 114.75 & 22.5 & 38.25 & 65.025 & 114.75 \\
\hline$\nu=0.49$ & $u$ & 5.13 & 5.07 & 5.05 & 5.07 & 10.70 & 10.70 & 10.70 & 10.69 \\
& $w$ & 70.69 & 72.48 & 73.01 & 72.61 & 70.90 & 72.69 & 73.22 & 72.82 \\
$\nu=0.45$ & $u$ & 6.08 & 6.00 & 5.97 & 5.98 & 10.81 & 10.80 & 10.80 & 10.80 \\
& $w$ & 50.14 & 51.56 & 52.04 & 51.80 & 50.09 & 51.51 & 51.98 & 51.74 \\
$\nu=0.41$ & $u$ & 7.16 & 7.05 & 7.01 & 7.03 & 10.96 & 10.94 & 10.94 & 10.94 \\
& $w$ & 35.95 & 37.08 & 37.48 & 37.34 & 35.73 & 36.85 & 37.25 & 37.11 \\
$\nu=0.37$ & $u$ & 8.38 & 8.24 & 8.19 & 8.20 & 11.16 & 11.14 & 11.13 & 11.13 \\
& $w$ & 26.03 & 26.93 & 27.27 & 27.19 & 25.70 & 26.58 & 26.92 & 26.85 \\
$\nu=0.33$ & $u$ & 9.76 & 9.59 & 9.52 & 9.53 & 11.43 & 11.39 & 11.38 & 11.38 \\
& $w$ & 19.04 & 19.75 & 20.03 & 20.00 & 18.62 & 19.32 & 19.60 & 19.56 \\
\hline
\end{tabular}

The combination $f_{X}=38.25, \nu=0.41$ represents our benchmark specification. $u$ is the unemployment rate, $w$ is the real wage.

Table 3: Labor market effects of export fixed costs with various degrees of external economies of scale. 
Individual bargaining
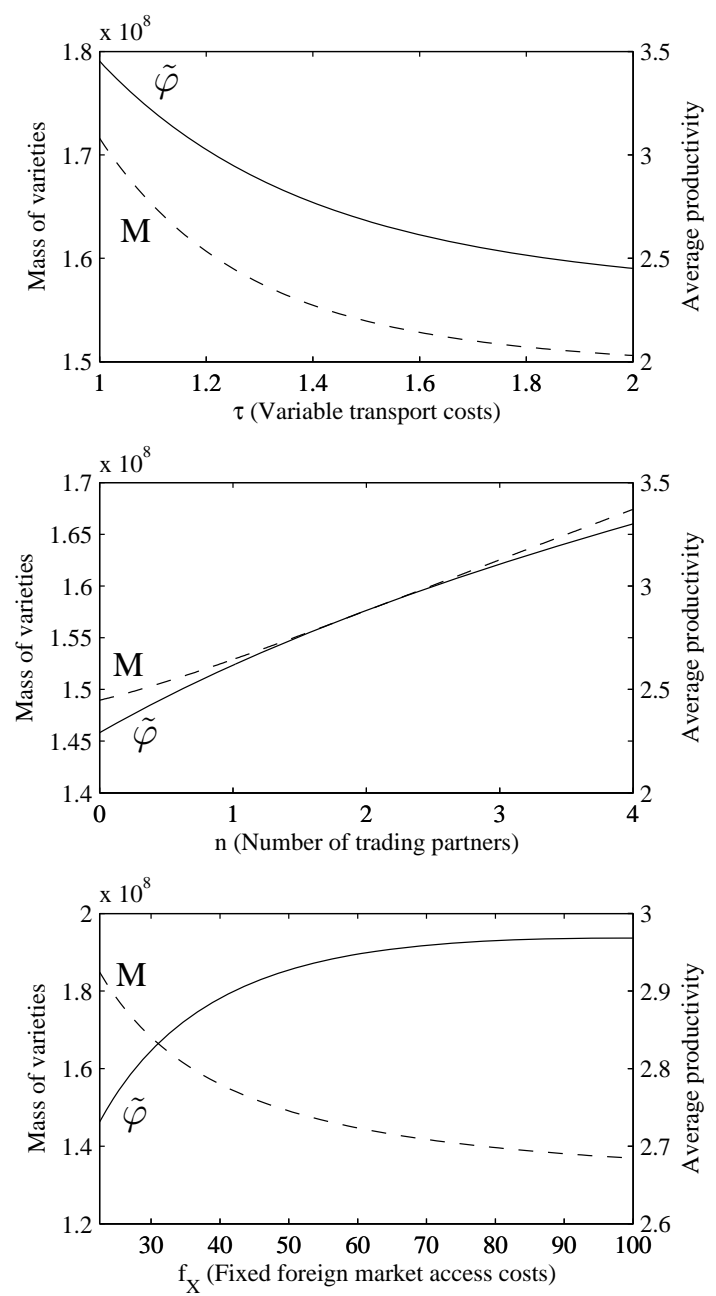

Collective bargaining
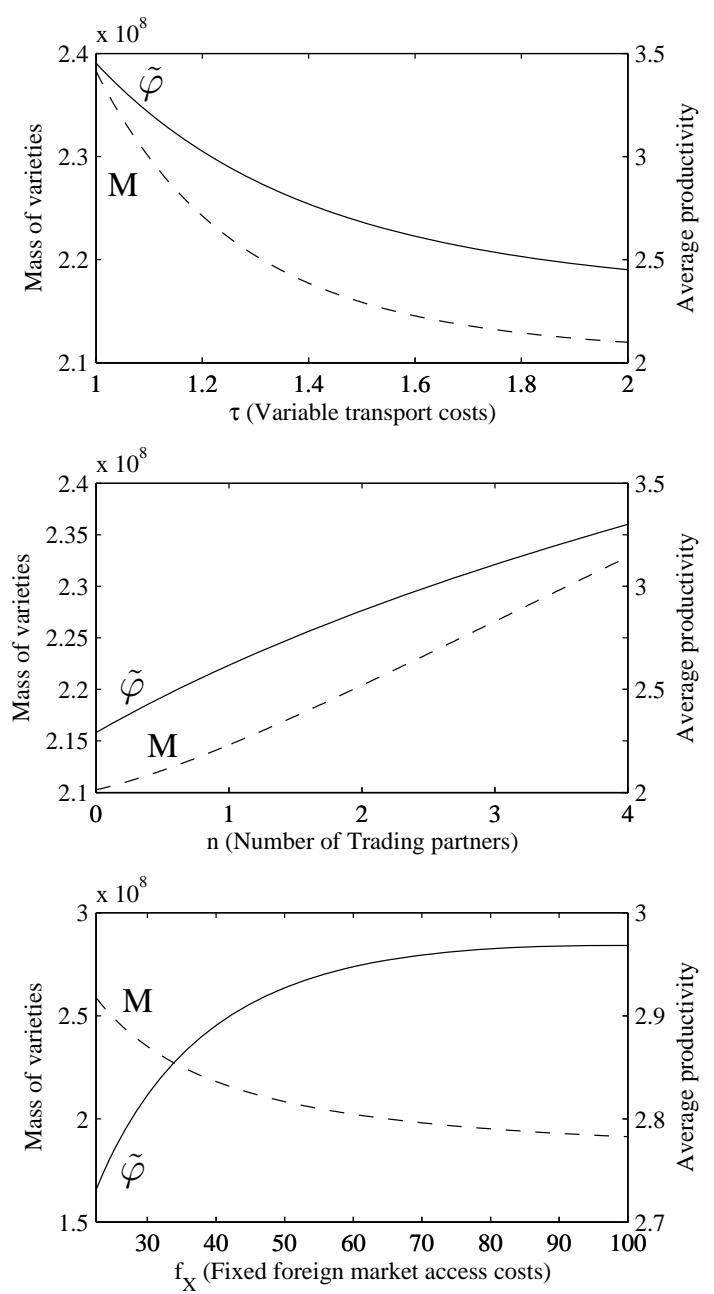

Figure 5: Simulation results: Product market effects of different trade liberalization scenarios 